\title{
AS TECNOLOGIAS DA INFORMAÇÃO E COMUNICAÇÃO (TICS) NAS AÇÕES EDUCATIVAS SOCIOAMBIENTAIS NA INSTITUIÇÃO DE ENSINO: UMA PROPOSTA SOB A ÓTICA DE INDICADORES E ANÁLISE DA MATRIZ SWOT
}

\section{ARTIGO ORIGINAL}

OLIVEIRA, Fábio Juvenal de ${ }^{1}$, ZOTES, Luís Perez ${ }^{2}$, FRANÇA, Sérgio Luiz Braga ${ }^{3}$, MEDINA, Fernando ${ }^{4}$, PACHECO, Miriam Carmen Maciel da Nóbrega ${ }^{5}$, ALVES, Francisco de Assis Bandeira ${ }^{6}$, RIBEIRO, Salvador Carlos Pires ${ }^{7}$

OLIVEIRA, Fábio Juvenal de. Et al. As tecnologias da informação e comunicação (Tics) nas ações educativas socioambientais na instituição de ensino: uma proposta sob a ótica de indicadores e análise da matriz Swot. Revista Científica Multidisciplinar Núcleo do Conhecimento. Ano 06, Ed. 06, Vol. 14, pp. 104-143. Junho de 2021. ISSN: 2448-0959, Link de acesso: https://www.nucleodoconhecimento.com.br/engenharia-de-producao/tecnologias-dainformacao, DOI: 10.32749/nucleodoconhecimento.com.br/engenharia-deproducao/tecnologias-da-informacao

\footnotetext{
${ }^{1}$ MSc. Sistema de Gestão- UFF, Graduado em Engenheiro de Produção-UFRJ.

${ }^{2}$ Professor DSc. Engenharia de Produção UFRJ.

${ }^{3}$ Professor DSc. Engenharia Civil UFF.

${ }^{4}$ Professor DSc. Engenharia de produção UFRJ.

${ }^{5}$ Professor DSc. Engenharia de Produção.

${ }^{6} \mathrm{MSc}$. Sistema de Gestão/Graduado em Matemática.

${ }^{7}$ Professor DSc. Ciências da Educação-Universidade Americana/Graduado em Arquitetura.
}

RC: 89489

Disponível em: https://www.nucleodoconhecimento.com.br/engenharia-deproducao/tecnologias-da-informacao 


\section{RESUMO}

Objetivo- Este trabalho tem como objetivo organizar e otimizar a utilização das tecnologias da informação e comunicação (TICs) na educação ambiental (EA) da temática resíduos sólidos (RS); delimitado ao contexto da Instituição Pública de Ensino (IE), CEFET-RJ. A investigação teve como foco o levantamento de indicadores de aspectos chaves neste processo educacional institucional, analisar as variáveis identificadas do ambiente interno e externo institucional em uma matriz SWOT e o estudo das TICs e suas capacidades no apoio à EA de RS na IE aos discentes. Metodologia- Trata-se de uma pesquisa exploratória com a abordagem qualitativa e quantitativa; sendo quanto aos meios, documental, bibliográfica, estudo de caso e surveys; aos fins, descritiva e aplicada. Os indicadores das variáveis foram submetidos a análise da matriz SWOT e foram obtidas por questionários específicos aplicados aos discentes, aos docentes especialistas em EA. Resultados- Os elementos colaborativos de TICs apresentados, viabilizam construir e dinamizar um espaço virtual referencial de conteúdos educacionais temático em RS. São apresentadas estratégias educacionais formais e informais de EA em RS na IE, interagindo com as TICs: o aplicativo institucional de descarte seletivo; peças publicitárias educacionais ambientais em resíduos sólidos com QR CODE; e a critério dos professores, sequências didáticas com objetos de aprendizagem na temática de resíduos sólidos, construídas por equipe interdisciplinar e ancoradas no portal digital.

Palavras-chave: Educação Ambiental, Instituição de Ensino, Tecnologias de Informação e Comunicação, Indicadores, Matriz SWOT.

\section{INTRODUÇÃO}

Os desafios ambientais enfrentados pelo mundo hoje abrangem todas as esferas da sociedade, com a educação ambiental desempenhando um papel fundamental na conscientização das gerações futuras (GUERRA et al., 2018). 
O surgimento de novas tecnologias de informação e comunicação ressignificam o modo de vida humano, a cultura e as relações com o espaço (CARVALHO; ARAÚJO, 2018). Nestas perspectivas, as tecnologias digitais, num enfoque interdisciplinar, têm sido invocadas como estratégia ao aprendizado ambiental.

Com a acelerada urbanização, a verticalização e o crescimento das atividades econômicas nas cidades, o descarte dos resíduos sólidos tornou-se um grande problema no mundo (BRINGHENTI et al., 2019). A geração anual mundial de resíduos sólidos (RS) deve aumentar dos 2,01 bilhões, em 2018, para 3,40 bilhões de toneladas até 2050 (KAZA; BHADA- TATA; VAN WOERDEN, 2018). No entanto, segundo os mesmos autores, pelo menos 33\% disso não é gerenciado em uma maneira ambientalmente segura. Cada brasileiro gera, em média, $1 \mathrm{~kg}$ de (RS) por dia, a partir do que, estima-se que a população brasileira gere aproximadamente 79 milhões de toneladas de RS por ano. apenas uma parte desse montante é destinada de forma ambientalmente adequada (BRASIL, 2019).

A falta de consciência e conhecimento sobre a destinação final dos resíduos coletados na cidade estão entre os principais motivos para a "não prática" da coleta seletiva (ARAÚJO; PIMENTEL, 2015). E algumas consequências dos descartes inadequados dos resíduos sólidos são: mau cheiro, alagamento das ruas e proliferação de insetos e animais vetores de doença, entre outros (ARAÚJJ; PIMENTEL, 2015).

As Instituições de Ensino (IE) estão tornando-se referência em práticas ambientalmente sustentáveis, contribuindo assim não só para a formação dos seus acadêmicos do ponto de vista teórico e prático (ROHRICH; TAKAHASHI, 2019).Concomitantemente, percebemos uma grande proliferação e abertura de novos espaços de comunicação para a Educação Ambiental, dentre os quais podemos citar o meio digital, a formação de redes e a multiplicação de sites na internet referentes ao tema (RODRIGUES; COLESANTI, 2008). 
As Tecnologias da Informação e Comunicação (TICs) servem como ferramentas educacionais de suporte, objetos de apoio, na forma de materiais de aprendizagem digitais (DANIELLA; GUTIÉRREZ-BRAOJOS; LYTRAS, 2018). A integração das TICs no processo de ensino e aprendizagem está ampliando a experiência educacional (KALOGIANNAKIS; PAPADAKIS, 2017).

A educação ambiental não é um tema a mais para compor uma grade curricular escolar, mas uma pauta que transcende a escola, o conceito de "educação" que figura no conceito de "educação ambiental" tem um sentido parecido ao de conscientização, formação, cultivação (MARCHIORATO, 2018).Assim, é preciso pensar no uso das TICs para a construção de conhecimentos e valores, buscando a articulação entre educação e comunicação, para que o indivíduo construa novos paradigmas, a fim de mudar seu olhar com relação ao meio ambiente (CARLI, 2013).

Este trabalho consiste um estudo de caso em uma escola técnica de ensino de grande porte, com intuito de aplicar conceitos oriundos da Educação Ambiental, com foco no uso de tecnologias da informação e comunicação na educação ambiental da temática de resíduos sólidos. Percebe-se que o ambiente educacional socioambiental possui uma grande importância no esforço das organizações na busca constante pela melhoria nos níveis de sustentabilidade ambiental. A Educação Ambiental é declarada direito de todos e componente essencial da educação nacional, devendo estar presente, de forma articulada, em todos os níveis e as modalidades do processo educativo, em caráter formal e não formal (BRASIL, 1999).

\section{METODOLOGIA}

Para o desenvolvimento desta pesquisa realizou-se uma revisão da literatura nas bases SciELO e Scopus no Portal de Periódicos da Coordenação de Aperfeiçoamento de Pessoas de Nível Superior (CAPES). Além de dissertações e fontes documentais, com o propósito de fornecer o embasamento teórico necessário ao tema. 
A pesquisa bibliográfica caracteriza-se como exploratória, já que o propósito primordial deste tipo de estudo é aprofundar uma ideia, constituir possibilidades e tornar o assunto mais familiar. A pesquisa bibliográfica é constituída por livros e artigos científicos em contraposição à diversidade de fontes possíveis numa pesquisa documental (GIL, 2009).

Lakatos e Marconi (2010) corroboram com esta afirmação ao argumentarem que a pesquisa bibliográfica é uma síntese dos principais trabalhos realizados sobre o tema, fornecendo dados atuais relevantes. A pesquisa bibliográfica utilizou de artigos científicos publicados nos últimos 5 anos, obtidos nas bases de dados: SciELO.ORG; SciELO Citation Index e Scopus. As palavras-chave na língua inglesa foram usadas na busca nas bases: SciELO Citation Index e na base Scopus. E na língua portuguesa, na SCIELO.ORG.

Devido à especificidade do tema, procurou-se selecionar os resultados com maior aderência ao tema da pesquisa, usando os termos: Gestão de resíduos Sólidos; Educação Ambiental; IES; Tecnologias da Informação e Comunicação: Realidade Aumentada. Acrescentaram-se livros e artigos, sem limites temporais, oriundos de referências bibliográficas da produção acadêmica analisada com o objetivo de apontar outras perspectivas.

Optou-se por usar elementos de abordagens de pesquisa qualitativa e quantitativa em um modo complementar. Esta abordagem mista permite que o estudo beneficie dos pontos fortes de ambas as abordagens durante a coleta, processamento e análise de dados.

De fato, em alguns casos, as fraquezas de um são compensadas pelos pontos fortes do outro. A respeito disso, Flick (2004) apontou que "o uso de mais de uma abordagem na coleta de dados e análise abre várias perspectivas para promover a qualidade na pesquisa". 
As etapas para a realização deste estudo foram as descritas a seguir: revisão da literatura com o objetivo de identificar os principais tópicos de interesse com relação ao tema; metodologia; construção dos questionários para a de coleta de dados ; efetivação da coleta de dados junto as amostras selecionadas; análise do contexto local; síntese dos resultados dos questionários; desenvolvimento de um conjunto de indicadores; análise SWOT( (dos termos em inglês Strengths, Weaknesses, Opportunities, Threats)das variáveis levantadas; análise das TICs na educação ambiental em resíduos sólidos(RS); apresentação da proposta das TICs de apoio a EA em RS; considerações finais.

\section{UMA BREVE ABORDAGEM CONCEITUAL DO USO DAS TICs NA EDUCAÇÃO AMBIENTAL DA TEMÁTICA RESÍDUOS SÓLIDOS}

Para que a gestão e o gerenciamento dos resíduos sólidos ocorram de maneira efetiva, faz-se necessário o engajamento dos cidadãos. Isto é fundamental para que se respeitem as prioridades previstas pela PNRS: não geração, redução, reutilização, reciclagem e tratamento dos resíduos sólidos, bem como disposição final ambientalmente adequada dos rejeitos (BRASIL, 2010). Deste modo, tal como recomenda Mombrini (2005), estratégias de sensibilização e incentivo à segregação correta dos resíduos na fonte estão sempre em desenvolvimento, num processo permanente e contínuo.

Estas ações desenvolvidas nas instituições de ensino, devem estar alinhadas ao eixo temático Gestão de Resíduos Sólidos, da Agenda 2030 para o Desenvolvimento Sustentável (ODS). Nesta instituição em estudo, a Divisão de Estratégia para Sustentabilidade Ambiental Institucional (DISAI), que está vinculada à Diretoria de Gestão Estratégica (DIGES) tem por objetivo transformar ideias em ações referentes à gestão e educação ambiental, desenvolvendo em cada indivíduo da comunidade a percepção socioambiental. 
Entre as ações, são mencionados alguns compromissos na instituição de ensino estudada, que merecem análise e acompanhamento institucional de suas execuções estratégicas e respectivos benefícios aos alunos e à sociedade sobre a temática resíduos sólidos:

a) Promover campanhas socioeducativas, com servidores, alunos e a sociedade, de sensibilização e educação ambiental, abordando o princípio dos $5 R^{\prime}$ s e visando à destinação seletiva dos resíduos, a partir da redução de desperdício e da coleta de óleo, dê coleta de resíduos eletroeletrônicos, de coleta de papel, de coleta de instrumentos de escrita usados sistematizadas no calendário acadêmico;

b) Realizar cursos de capacitação a fim de orientar sobre a importância da redução da geração, armazenamento, manuseio adequado de pilhas, baterias, lâmpadas, resíduos tóxicos, e ações preventivas e corretivas em caso de acidentes;

c) Trabalhar a questão de resíduos sólidos, de forma interdisciplinar, em sala de aula;

d) Manter canal de divulgação digital e on-line para orientação permanente à comunidade acadêmica para coleta interna e armazenamento, além dos locais de recebimentos de resíduos no campus (CEFET/RJ, 2015).

Há necessidades essenciais e urgentes de aumentar a conscientização e chamar a atenção sobre como inovar e energizar as TICs para melhor ajudar todas as nações a alcançar os ODS até 2030 (WU et al., 2018). O campo da educação não é imune a avanços na sofisticada tecnologia da informação e comunicação (TICs) (DANIELA et al., 2018).

O papel das administrações públicas locais e centrais na promoção do desenvolvimento sustentável precisam de habilidades e competências novas e criativas (PĂVĂLOAIA et al., 2019).

Para melhor compreensão do panorama ambiental no mundo, torna-se fundamental buscar ferramentas que estrategicamente apoiem a educação ambiental, incentivando desta forma, a sensibilização e aprendizagem da temática gestão e gerenciamento de RC: 89489

Disponível em: https://www.nucleodoconhecimento.com.br/engenharia-deproducao/tecnologias-da-informacao 
resíduos sólidos, viabilizando constructos que sistematizem e conduzam a EA no contexto formal e informal para os discentes.

A inserção das mídias digitais, de conteúdo educacional ambiental, no contexto local e da sociedade, deve trazer benefícios à dinâmica de ensino do campus ao disponibilizá-las como ferramenta em projetos para a promoção, orientação, conscientização e sensibilização em prol das políticas de EA e de gestão e gerenciamento dos resíduos sólidos.

A comunidade educacional reconheceu que os dispositivos móveis e seus aplicativos podem ser usados para a educação ambiental, bem como na educação para o desenvolvimento sustentável (KALOGIANNAKIS; PAPADAKIS, 2017).

A formação de professores para a utilização das TICs, em especial, as tecnologias móveis pressupõem que ocorra uma ressignificação do trabalho docente (CARVALHO, 2017).

No contexto da relevância do estudo da educação ambiental formal e informal com as ferramentas das TICs, é concebida a ideia de ressignificação do trabalho docente, com base na conceituação de Tardif e Lessard (2005), ao definirem o trabalho dos professores como:

Um trabalho interativo que envolve aspectos formais e informais, e que se trata, portanto, ao mesmo tempo, de um trabalho flexível e codificado, controlado e autônomo, determinado e contingente. Assim, o ensino surge como uma tarefa fortemente marcada pelas interações humanas na qual o saber dos professores está "[...] relacionado com a pessoa e a identidade deles, com suas experiências de vida e com a sua história profissional, com as suas relações com os alunos em sala de aula e com os outros atores escolares na escola", e, sobretudo, pela presença das tecnologias móveis na escola (TARDIF; LESSARD, 2005).

A importância de estudar e utilizar o potencial das tecnologias de mídia social é evidente, em 2018, estima-se que 2,65 bilhões de pessoas estavam usando as mídias

RC: 89489

Disponível em: https://www.nucleodoconhecimento.com.br/engenharia-deproducao/tecnologias-da-informacao 
sociais em todo o mundo, número projetado para aumentar para quase 3,1 bilhões em 2021 (CLEMENT, 2019).

As mídias sociais permitem o compartilhamento de informações sobre questões ambientais, levam ao aumento do conhecimento sobre os impactos das ações humanas (como o comportamento do consumidor) e constroem conhecimento procedimental sobre como reduzir o impacto ambiental (PEARSON et al., 2016). Esse processo de construção, viabilizam caminhos personalizados de aprendizado ambiental na temática resíduos sólidos.

Essas informações online levam à atividade offline, removendo barreiras de conhecimento, fortalecendo as normas ambientais, especialmente para indivíduos que não tenham conhecimento de um problema (PEARSON et al., 2016).

A Figura 1 mostra a relação entre os assuntos Gestão e Gerenciamento de Resíduos Sólidos (RS), Instituição de Ensino Superior (IE), Tecnologias da Informação e Comunicação (TICs), Educação Ambiental e Discentes tratadas neste estudo. 


Figura 1 - $\quad$ Relação entre os temas tratados

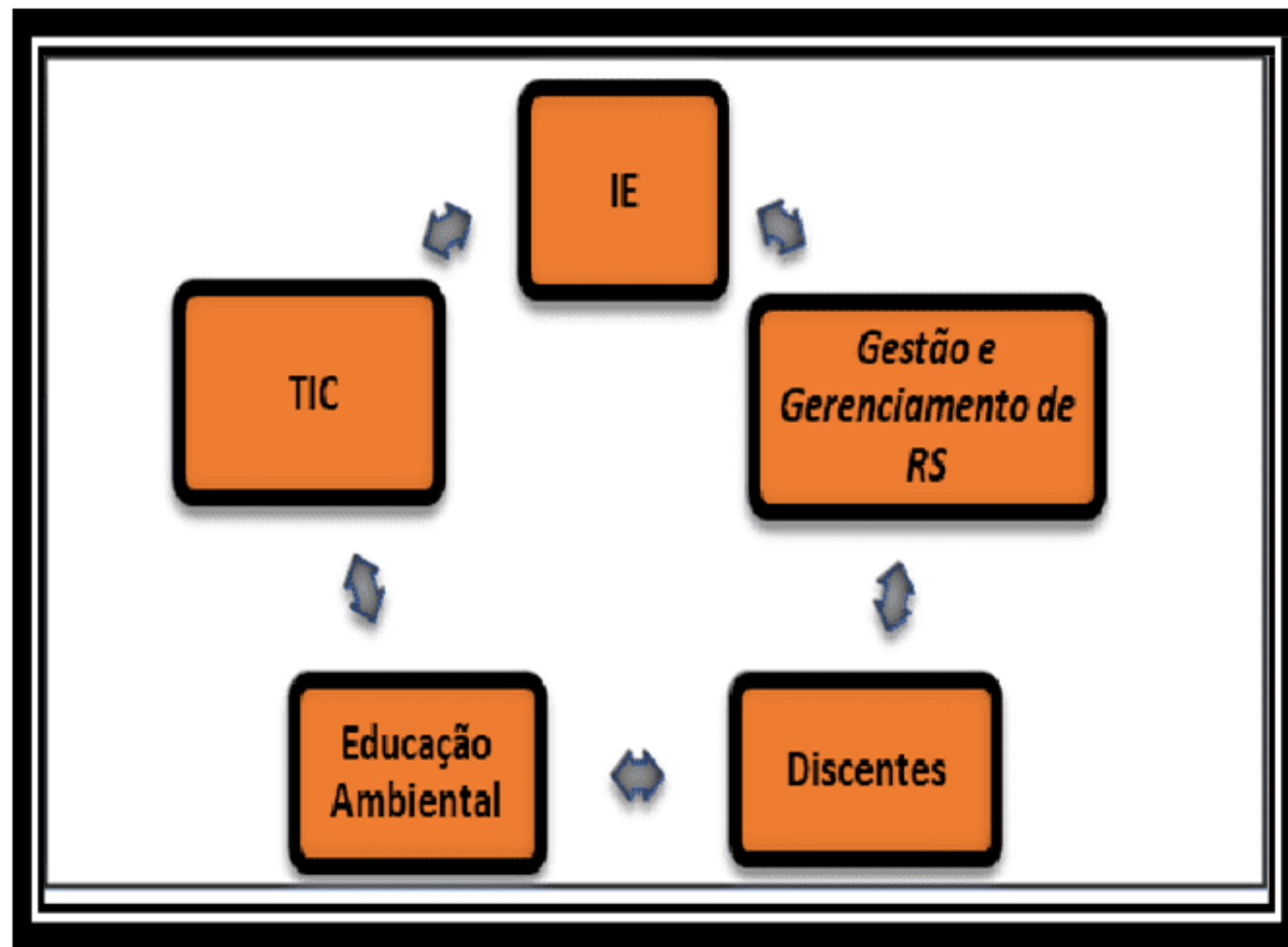

Fonte: Elaborado pelos autores deste Trabalho, 2021.

As Instituições Públicas de Ensino (IE) como organizações públicas devem adequar tanto sua gestão como seu ensino às legislações ambientais vigentes e desempenhar iniciativas de difusão de práticas sustentáveis (RIBEIRO et al., 2018).

Logo, tais instituições desempenham papéis que vão além do ensino e da formação profissional, devendo, perante a sociedade que a financia, construir uma conscientização social e ambiental no momento da capacitação dos futuros profissionais e tomadores de decisão, a fim de perpetuar tal cultura. Isso porque, também são geradoras de impactos ambientais. Através dos laboratórios de diferentes áreas, hospitais universitários, clínica da área de saúde, bibliotecas, restaurantes 
universitários e outros setores, gerando uma diversidade de resíduos sólidos, líquidos e gasosos (GUTIERRES; CABRAL; SILVA, 2019).

Como a cultura do desenvolvimento sustentável deve ser vivenciada diariamente nas instituições de ensino, este é um ambiente para a educação ambiental na temática resíduos sólidos

\subsection{AS TICs, O APRENDIZADO E A EDUCAÇÃO AMBIENTAL}

O significado que as TICs (Tecnologias da Informação e Comunicação) têm na sociedade do conhecimento é consequência direta da digitalização, transmídia, crescimento exponencial das tecnologias e penetração da web 2.0 (BARROSOOSUNA et al., 2019). As instituições acadêmicas estão cada vez mais integrando novas tecnologias de informação e comunicação (TICs) em seus sistemas educacionais (ÓRUS et al., 2016).

Tecnologias como "análise de aprendizado", "gamificação", "videogames sérios" ou "robótica" estão sendo rapidamente incorporadas ao ensino (BARROSO-OSUNA et al., 2019). As realidades físicas e digitais são misturadas através de diferentes recursos, como imagens, diferentes objetos tridimensionais, incorporação de $Q R$ Code, leituras térmicas ou coordenadas GPS (GARCIA, 2016). Ou qualquer outra forma contemporânea de transmissão e ferramentas tecnológicas com fins educacionais, que devem ser considerados e interligados.

Nessa direção, os meios de comunicação, sobretudo, as redes sociais e aplicativos são significativos no auxílio desta tarefa, principalmente por terem um alto alcance de público em pouco tempo (STEFANI; BERNARDES; BERNARDO, 2016). A tecnologia assim, remete a uma presença contínua ao acesso e compartilhamento do aprendizado. 
A educação ambiental se faz valer tanto de maneira formal, permeando as várias disciplinas das instituições de ensino, como não-formal, por meio da sensibilização da coletividade sobre as questões ambientais e estímulo a sua organização e participação na defesa da qualidade do meio ambiente (BRASIL, 1999).

\section{ESTUDO DE CASO}

A presente seção propõe apresentar de forma resumida os resultados apontados a partir da realização da coleta e análise de dados, dando enfoque aos objetivos do estudo e análise dos indicadores dos questionários. Para tanto, optou-se inicialmente pela estruturação dos dados em tópicos e índices.

Com os dados foram construídos os indicadores das variáveis, e agrupadas em "aspectos chave". As variáveis consideradas e estabelecidas se apresentam neste estudo como Forças e Fraquezas (Ambiente Interno Institucional) e nas Oportunidades e Ameaças (Ambiente Externo). Os dados obtidos foram alocados e analisados através da ferramenta SWOT de acordo com os dois ambientes, onde se tem como cenários referenciais, os espaços de ensino formal e informal na instituição. Por fim, foram realizados procedimentos estatísticos e efetuada as análises das TICs na EA em RS.

Destarte, as informações colhidas qualificam os resultados e discussões, de forma que as seções e procedimentos descritos, sejam suporte para a validação da proposta de sistematizar as Tecnologias da Informação e Comunicação na Educação Ambiental da Temática de Resíduos Sólidos na Instituição.

\subsection{SÍNTESE DOS QUESTIONÁRIOS}

Este item visa apresentar um resumo, com a tabulação dos tópicos abordados, em forma de indicadores informacionais dos dados, para em seguida ampliar as análises dos dados dos questionários aplicados aos discentes e docentes da instituição. $\mathrm{O}$

RC: 89489

Disponível em: https://www.nucleodoconhecimento.com.br/engenharia-deproducao/tecnologias-da-informacao 
principal objetivo dos conjuntos de indicadores desenvolvidos é mostrar as informações relevantes para gestores, políticos e público em geral, portanto, uma etapa importante da metodologia para a divulgação dos resultados (CIFRIAN; ANDRES; VIGURI, 2015).

A população é composta principalmente por discentes, no total 2470 , sendo 649 estudantes do ensino médio técnico maiores de idade; os alunos constituem o principal alvo do estudo, pois são os principais beneficiados das ações educacionais promovidas pela divisão de sustentabilidade da IE; e os maiores usuários na utilização de recursos digitais de aprendizado para promover capilaridade à educação ambiental. Para a amostra da população discentes buscou-se alcançar, no total, 270 estudantes (representando mais de $10 \%$ da população total).

E como população no estudo temos também 458 docentes na Instituição campus Maracanã. Na população, docentes foram intencionalmente escolhidos por áreas de ensino, com objetivo de alcançar para a amostra, quarenta e seis professores acadêmicos (10\% da população total). Foram almejados: dez docentes da área de TICs, dez da área de Ciências Biológicas, seis de Química e vinte de áreas diversas, profissionalizantes, graduação e pós-graduação.

O estudo utilizou procedimentos de amostragem não probabilística para gerar uma amostra que será usada para coleta de dados. Amostragem não probabilística é aquela em que a seleção dos elementos da população para compor a amostra depende ao menos em parte do julgamento do pesquisador ou do entrevistador no campo (MATTAR, 1996, p. 132).

A amostragem por conveniência é adequada e frequentemente utilizada para geração de ideias em pesquisas exploratórias, segundo Aaker, Kumar e Day (1995, p. 376), uma vez que esse procedimento consiste em simplesmente contatar unidades convenientes da amostragem, é possível recrutar respondentes tais como estudantes em sala de aula, a amostra por conveniência é empregada quando se deseja obter

RC: 89489

Disponível em: https://www.nucleodoconhecimento.com.br/engenharia-deproducao/tecnologias-da-informacao 
informações de maneira rápida e barata. Especificamente, foram implantados métodos de amostragem intencional e de conveniência.

Com relação aos questionários enviados aos discentes e docentes eles são constituídos por questões fechadas, e elaboradas através de escala de Likert, ancoradas pelos estudos do referencial teórico. O questionário de cada alvo populacional utilizado nesta pesquisa, tem por base o aplicativo de pesquisas on-line chamado Google Forms, escolhido por tratar-se de ferramenta na qual é possível encaminhar o link da pesquisa através de correio eletrônico para o público-alvo e monitorar o seu preenchimento e resultados.

Tabela 1- Público-alvo entrevistado

\begin{tabular}{|ccccc}
\hline Níveis de Ensino & $\begin{array}{c}\mathrm{N}^{\circ} \\
\text { Questionários } \\
\text { enviados aos } \\
\text { alunos }\end{array}$ & $\begin{array}{c}\mathrm{N}^{\circ} \text { Discentes } \\
\text { respondentes }\end{array}$ & $\begin{array}{c}\mathrm{N}^{\circ} \\
\text { Questionários } \\
\text { enviados aos } \\
\text { Professores }\end{array}$ & $\begin{array}{c}\mathrm{N}^{\circ} \text { Docentes } \\
\text { respondentes }\end{array}$ \\
\hline Ensino médio & 168 & 31 & 78 & 22 \\
Ensino Superior & 134 & 32 & 45 & 8 \\
\hline Pós-Graduação & 43 & 10 & 18 & 6 \\
Totais & 345 & $\mathbf{7 3}$ & 141 & $\mathbf{2 5 , 5 3 \%}$ \\
\hline \% de Retorno & $\mathbf{7 3 / 3 4 5}$ & $\mathbf{2 1 , 1 5 \%}$ & $\mathbf{3 6 / 1 4 1}$ & \\
\hline
\end{tabular}

Fonte: Elaborado pelos autores deste Trabalho, 2021.

Foram enviados para 345 alunos o link do questionário aos discentes através de emails ou contatos de WhatsApp de turmas fornecidos pelos docentes. Esta estratégia de distribuição de questionários aos alunos, foi necessária neste período com a instituição fechada em suas atividades presenciais, devido a pandemia COVID-19.

O público submetido à pesquisa foram: alunos e professores dos níveis de ensino médio, da graduação e da pós-graduação (Tabela 1). 
Quadro 1 - Perguntas do questionário aos discentes em relação à literatura

\begin{tabular}{|c|c|}
\hline Pergunta & Autores dos Artigos \\
\hline $\begin{array}{l}\text { 8.Qual(is) dispositivo(s) você utiliza para se manter } \\
\text { informado (a): }\end{array}$ & $\begin{array}{l}\text { WIRTZ e BIRKMEYER (2018), PEARSON et al. } \\
\text { (2016), CABERO-ALMENARA et al. (2019). }\end{array}$ \\
\hline $\begin{array}{l}\text { 9.Qual é a qualidade de sua internet durante o mês } \\
\text { para realizar seus acessos em qualquer dispositivo: }\end{array}$ & $\begin{array}{l}\text { PEARSON et al. (2016); CABERO-ALMENARA et } \\
\text { al. (2019). }\end{array}$ \\
\hline \multicolumn{2}{|l|}{$\begin{array}{l}\text { 10. Com relação a busca de informações ou } \\
\text { estudos, qual a frequência que? (Muita frequência, } \\
\text { com frequência, Ocasionalmente, Raramente, } \\
\text { Nunca) }\end{array}$} \\
\hline $\begin{array}{l}\text { a) Você pesquisa videos explicativos no YouTube e } \\
\text { tira dúvidas. }\end{array}$ & $\begin{array}{l}\text { TAN (2013); ÓRUS et al. (2016); STEFANI et al. } \\
\text { (2016); PEARSON et al. (2016). }\end{array}$ \\
\hline $\begin{array}{l}\text { b) Você compartilha conteúdos: áudios, vídeos } \\
\text { explicativos por meio de aplicativos como Facebook, } \\
\text { Twitter ou WhatsApp }\end{array}$ & $\begin{array}{l}\text { SHANA et al. (2015); RIGA et al. (2016); } \\
\text { PEARSON et al. (2016). }\end{array}$ \\
\hline $\begin{array}{l}\text { c) Você acessa endereços eletrônicos (links) ou QR } \\
\text { Code que levem às informações }\end{array}$ & $\begin{array}{l}\text { PEARSON et al. (2016); GARCIA (2016); GU et al. } \\
\text { (2016); RABU et al. (2019); STEFANI et al. (2016) }\end{array}$ \\
\hline $\begin{array}{l}\text { d) Salva arquivos ou links pelo Smartphone evitando } \\
\text { o uso de impressoras, papel, energia e tinta. }\end{array}$ & TURAN ÇIMSIR et al. (2019); RABU et al. (2019). \\
\hline \multicolumn{2}{|l|}{$\begin{array}{l}\text { 11. Qual o grau de importância das seguintes } \\
\text { sugestões para um espaço virtual educativo } \\
\text { dinâmico, com recursos tecnológicos, no apoio a } \\
\text { educação ambiental em resíduos sólidos na } \\
\text { instituição de ensino }\end{array}$} \\
\hline $\begin{array}{l}\text { a) Que você acesse e navegue por explicações } \\
\text { ambientais atualizadas em: artigos cientificos e textos, } \\
\text { vídeos, sites e livros. }\end{array}$ & $\begin{array}{l}\text { PÅVĂLOAIA et al. (2019); NWAFOR et al. (2019). } \\
\text { PEARSON et al. (2016). CARVALHO et al. 2017); }\end{array}$ \\
\hline $\begin{array}{l}\text { b) Informe via smartphone, os locais, por } \\
\text { proximidade, dos pontos de coletas seletivas na } \\
\text { instituição e suas características. }\end{array}$ & $\begin{array}{l}\text { LIAO et al. (2019); ROCHA (2015); FARRELY } \\
\text { (2016), LEMOS (2007); CARVALHO et al. (2018); } \\
\text { ZAGO et al. (2019). }\end{array}$ \\
\hline $\begin{array}{l}\text { c) Que as navegações digitais associem lixo e esgoto } \\
\text { aos impactos socioambientais. }\end{array}$ & $\begin{array}{l}\text { DEMOLY et al. (2018); ZANELA (2007); } \\
\text { ESPINOSA et al. (2014). NWAFOR et al. (2019); } \\
\text { REBEHY et al. (2017). }\end{array}$ \\
\hline $\begin{array}{l}\text { d) Permita compartilhar aprendizados ambientais em } \\
\text { redes sociais }\end{array}$ & BRANDALISE (2019); GREENHOW et al. (2017); \\
\hline $\begin{array}{l}\text { e) Que os cartazes educacionais nos locais de coleta } \\
\text { de residuos contenham links, QR Code, GPS, } \\
\text { aprimorando explicação do descarte local online com } \\
\text { imagens e áudios }\end{array}$ & $\begin{array}{l}\text { BARROSO-OSUNA et al. (2019); MAQUILÓN et al. } \\
\text { (2017); CARVALHO et al. (2018); JEPSON et al. } \\
\text { (2015); BUCHANAN et al (2019); GARCIA (2016); } \\
\text { SHANA et al. (2015); CABERO-ALMENARA et al. } \\
\text { (2019); CARVALHO et al (2017), FARRELLY } \\
\text { (2015); LEMOS (2007); ZAGO et al. (2019). }\end{array}$ \\
\hline \multicolumn{2}{|l|}{$\begin{array}{l}\text { 12. Qual o nivel de frequência que você tem } \\
\text { dúvida? }\end{array}$} \\
\hline
\end{tabular}

Fonte: Elaborado pelos autores deste Trabalho, 2021.

Um total de 73 alunos participaram dessa pesquisa: foram, trinta e um (31) alunos do Ensino médio; trinta e dois (32) alunos no Ensino superior; dez (10) alunos da Pós-

Disponível em: https://www.nucleodoconhecimento.com.br/engenharia-deproducao/tecnologias-da-informacao 
graduação. Em relação aos professores: no Ensino médio foram vinte e dois (22); no Ensino superior foram oito (8) e na Pós-Graduação seis (6).

Quadro 1 - Perguntas do questionário aos discentes em relação à literatura (continuação)

\begin{tabular}{|c|c|}
\hline Pergunta & Autores dos Artigos \\
\hline $\begin{array}{l}\text { a) Ao jogar fora o lixo nos coletores simples } \\
\text { diferenciados, descartar na categoria de lixo correta: } \\
\text { seco, úmido, reciclável e não reciclável. }\end{array}$ & $\begin{array}{l}\text { BRINGHENTI et al. (2019). NWAFOR et al. (2019); } \\
\text { SILVA (2018); REBEHY et al. (2017); ZAGO et al. } \\
\text { (2019). }\end{array}$ \\
\hline $\begin{array}{l}\text { b) Ao descartar o lixo nos coletores multisseletivos, } \\
\text { identificar padrões de cores normatizados ou símbolos } \\
\text { utilizados para identificar composição ou } \\
\text { periculosidade }\end{array}$ & $\begin{array}{l}\text { BRINGHENTI et al. (2019); NWAFOR et al. (2019); } \\
\text { (SILVA, 2018); REBEHY et al. (2017); ZAGO et al. } \\
\text { (2019). }\end{array}$ \\
\hline $\begin{array}{l}\text { c) Ao interpretar rotulagens ambientais informativas } \\
\text { nas embalagens de produtos comercializados }\end{array}$ & SODRÉ (1997); CORREA (1998). \\
\hline $\begin{array}{l}\text { d) Na mudança de atitudes de consumo e aumento da } \\
\text { vida útil de produtos e na redução do descarte } \\
\text { daqueles que prejudicam a saude e o meio ambiente }\end{array}$ & $\begin{array}{l}\text { ZHANG et al. (2019); REBEHY et al. (2017); KLEIN } \\
\text { et al. (2018); ALBANO et al. (2018). }\end{array}$ \\
\hline $\begin{array}{l}\text { e) Na separação de embalagens, matéria orgânica e } \\
\text { óleo de cozinha usado }\end{array}$ & $\begin{array}{l}\text { BRINGHENTI et al. (2019); NWAFOR et al. (2019); } \\
\text { ZAGO et al. (2019); SILVA (2018); KLEIN et al. } \\
\text { (2018). }\end{array}$ \\
\hline $\begin{array}{l}\text { f) Em perceber os impactos socioambientais do lixo e } \\
\text { esgoto não tratados lançados "silenciosamente" no } \\
\text { solo, mares e rios onde vivemos e a responsabilidade } \\
\text { da sociedade }\end{array}$ & $\begin{array}{l}\text { ESPINOSA et al. (2014); REBEHY et al. (2017); } \\
\text { NWAFOR et al. (2019); GUTIERRES et al. (2019); } \\
\text { ALBANO et al. (2018). }\end{array}$ \\
\hline $\begin{array}{l}\text { g) Onde ficam os pontos de coletas seletivas do tipo: } \\
\text { óleo usado, papéis, baterias, entre outros dentro da } \\
\text { minha instituição }\end{array}$ & $\begin{array}{l}\text { BRINGHENTI et al. 2019; ZHANG et al. (2017) e } \\
\text { ZSÓKA et al. (2013); ASSAD (2016); } \\
\text { ZAGO et al. (2019). }\end{array}$ \\
\hline \multicolumn{2}{|l|}{$\begin{array}{l}\text { 13. Quais são os níveis de frequência que em } \\
\text { espaços da sua instituição de ensino ela promove } \\
\text { campanhas: }\end{array}$} \\
\hline $\begin{array}{l}\text { a) De sensibilização e educação ambiental em } \\
\text { resíduos sólidos. }\end{array}$ & IARED et al. (2011); ROCHA, (2015); \\
\hline $\begin{array}{l}\text { b) Que informa claramente localizações do descarte } \\
\text { de todos os resíduos(mapeamento), inclusiveresíduos } \\
\text { provenientes de oficinas / laboratórios de ensino. }\end{array}$ & $\begin{array}{l}\text { ZHANG et al. (2017) e ZSÓKA et al. (2013); LIAO } \\
\text { et al. 2019); FARRELLY (2015); LEMOS (2007); } \\
\text { ZAGO et al. (2019); GUTIERRES et al. (2019); } \\
\text { NWAFOR et al. (2019). GOBIRA et al. (2017). }\end{array}$ \\
\hline $\begin{array}{l}\text { c) Que utilize os laboratórios de informática ou } \\
\text { tecnologias em sala de aula para ensino de assuntos } \\
\text { relacionados a educação ambiental em resíduos } \\
\text { sólidos }\end{array}$ & $\begin{array}{l}\text { CAFURE et al. (2015); PEARSON et al. (2016) } \\
\text { GOBIRA et al. (2017). }\end{array}$ \\
\hline
\end{tabular}

Fonte: Elaborado pelos autores deste Trabalho, 2021.

Segundo Lakatos e Marconi (2010), em média, os questionários enviados pelo pesquisador alcançam $25 \%$ de devolução. As perguntas dos questionários aos

RC: 89489

Disponível em: https://www.nucleodoconhecimento.com.br/engenharia-deproducao/tecnologias-da-informacao 
discentes e aos docentes abordavam questões sobre os conhecimentos e atitudes. Foram elaboradas com embasamentos provenientes de artigos utilizados da revisão da literatura realizada, e estão descritos no Quadro 1 e Quadro 2 respectivamente.

Quadro 2 - Perguntas do questionário aos docentes em relação à literatura

\begin{tabular}{|c|c|}
\hline Pergunta & Autores dos Artigos \\
\hline $\begin{array}{l}\text { 5.Teve algum treinamento na área de informática e } \\
\text { ensino com uso de TICs (Tecnologias da Informação } \\
\text { e Comunicação) nos últimos anos: }\end{array}$ & $\begin{array}{l}\text { DANIELA et al. (2018); GREENHOW e ASKARI } \\
\text { (2017); TARDIF e LESSARD (2005). }\end{array}$ \\
\hline $\begin{array}{l}\text { 6.Qual a avaliação da infraestrutura das TICs na } \\
\text { instituição para o ensino em sala de aula e laboratórios: }\end{array}$ & $\begin{array}{l}\text { BARROSO-OSUNA et al. (2019); CABERO- } \\
\text { ALMENARA et al. (2019). }\end{array}$ \\
\hline $\begin{array}{l}\text { 7.Qual (is) aparato (s) tecnológicos e mídia (s) } \\
\text { elencados abaixo você julga importante na educação } \\
\text { ambiental em gestão de resíduos sólidos aos discentes } \\
\text { na instituição, que viabilize qualidades de apoio ao } \\
\text { aprendizado como, compartilhamento, interatividade e } \\
\text { alcance dos conteúdos educacionais ambientais? } \\
\text { (Selecione mais de uma opção caso necessário) }\end{array}$ & $\begin{array}{l}\text { ZANELA (2007); PĂVĂLOAIA et al. (2019); } \\
\text { CARVALHO (2017); GREENHOW e ASKARI } \\
\text { (2017); RABU et al. (2019); TURAN ÇIMSIR e } \\
\text { UZUNBOYLU (2019); PEARSON et al. (2016). }\end{array}$ \\
\hline $\begin{array}{l}\text { 8.Você teve algum (uns) curso(os) de capacitação nos } \\
\text { últimos } 5 \text { anos, a fim de orientar sobre repensar, } \\
\text { reduzir, reutilizar, reciclar, tratar, dispor os resíduos } \\
\text { sólidos diversos, como pilhas, baterias, lâmpadas, } \\
\text { óleos diversos, resíduos tóxicos, entre outros e ações } \\
\text { corretivas em caso de acidentes? }\end{array}$ & $\begin{array}{l}\text { RIBEIRO et al. (2018); KLEIN et al. (2018); ZHANG } \\
\text { et al. (2019); ASSAD (2016); TAUCHEN e } \\
\text { BRANDLI (2006). GOBIRA et al. (2017); CAFURE } \\
\text { e PATRIARCHA-GRACIOLLI (2015); TARDIF; } \\
\text { LESSARD (2005). }\end{array}$ \\
\hline $\begin{array}{l}\text { 9.Visando à aprendizagem da gestão de resíduos } \\
\text { sólidos aos discentes com auxílio de uma plataforma } \\
\text { digital que possua tecnologias e recursos didáticos em } \\
\text { multimidias selecionados por corpo docente } \\
\text { interdisciplinar da instituição de ensino, neste cenário: } \\
\text { Qual o nivel de importância do apoio das TICs na } \\
\text { educação ambiental aos alunos nos seguintes } \\
\text { aspectos? Conhecimento, Habilidades, práticas } \\
\text { atitudes e valores Éticos. }\end{array}$ & $\begin{array}{l}\text { BUCHANAN et al. (2019); CEBRIÁN e JUNYENT } \\
(2015) ; \quad \text { PAREDES-LABRA et al. (2018); } \\
\text { CAMILLERI e CAMILERI (2017); TURAN ÇIMSIR } \\
\text { e UZUNBOYLU (2019); GUERRA et al. (2018); } \\
\text { WIRTZ e BIRKMEYER (2018); GREENHOW e } \\
\text { ASKARI (2017); LIAO e LI. (2019); MAUROLI e } \\
\text { DUROY (2019); JEPSON e LADLE (2015); CARLI } \\
\text { (2013). }\end{array}$ \\
\hline $\begin{array}{l}\text { 10.Sempre colocando o pedagógico acima do } \\
\text { tecnológico, qual é o seu nivel de concordância em } \\
\text { relação ao uso da informática (Tecnologias da } \\
\text { Informação e Comunicação) no apoio à Educação } \\
\text { Ambiental em residuos sólidos aos discentes na } \\
\text { instituição? }\end{array}$ & $\begin{array}{l}\text { ROCHA (2015); MAUROLI e DUROY (2019); } \\
\text { TURAN CCIMSIR e UZUNBOYLU (2019); } \\
\text { GREENHOW e ASKARI (2017); JEPSON e LADLE } \\
\text { (2015); PEARSON et al. (2016); CARVALHO e } \\
\text { ARAÜJO (2018); ZHANG et al. (2019); TAN (2013); } \\
\text { GREEENHOW e ASKARI (2017); PAVĂLOAIA et } \\
\text { al. (2019); KALOGIANNAKIS; PAPADAKIS } \\
(2017) .\end{array}$ \\
\hline
\end{tabular}

Fonte: Elaborado pelos autores deste Trabalho, 2021.

RC: 89489

Disponível em: https://www.nucleodoconhecimento.com.br/engenharia-deproducao/tecnologias-da-informacao 


\subsubsection{TÓPICOS FOCADOS}

Nesta síntese dos dados dos questionários aplicados, utiliza-se a análise dos resultados por índices, através do agrupamento dos aspectos chave enfocados nas questões, definidos como eixo focado.

Optou-se por empregar, como estratégia para análise dos resultados, e no cálculo dos indicadores, o procedimento do ranking médio (RM).

Quadro 3 - Eixos estruturados - Síntese dos questionários ALUNOS Likert 1 a 5

\begin{tabular}{|l|l|l|l|l|}
\hline \multicolumn{1}{|c|}{ Eixo Focado } & \multicolumn{1}{|c|}{$\begin{array}{c}\text { Descrição (Conteúdo) abordados } \\
\text { em escala Likert 1 a 5 }\end{array}$} & \multicolumn{1}{|c|}{ Aspectos Chave } & RM & RM \\
Eixo
\end{tabular}

Fonte: Elaborado pelos autores deste Trabalho, 2021.

Para cada eixo (Tópicos), foram selecionadas afirmativas de acordo com os conteúdos principais dos questionários. Destarte, o eixo focado se apresenta como uma variável. 
Nos Quadros 3, 4, 5 e 6 apresentam-se cada um dos eixos estruturados por questão abordada, no intuito de facilitar a análise do conjunto de assertivas, são apresentados os escores calculados pelo ranking médio (RM) ou média ponderada (MP) dos aspectos chave respondidos na escala Likert, indicando assim uma avaliação e melhor entendimento das respostas dentro de cada tipo de escala abordada.

Quadro 4 - Eixos estruturados -Síntese dos questionários ALUNOS (Likert 1 a 6)

\begin{tabular}{|c|c|c|c|c|}
\hline Eixo Focado & $\begin{array}{c}\text { Descrição (Conteúdo) abordados } \\
\text { em escala Likert } 1 \text { a } 6\end{array}$ & Aspectos Chave & $\mathbf{R M}$ & $\begin{array}{l}\text { RM } \\
\text { Eixo }\end{array}$ \\
\hline \multirow{3}{*}{$\begin{array}{l}\text { Percepção dos Alunos } \\
\text { da EA em RS } \\
\text { promovidas na IE }\end{array}$} & \multirow{3}{*}{$\begin{array}{l}\text { Neste eixo busca as ações de EA em } \\
\text { RS oriundas da Instituição de Ensino. } \\
\text { Gestão e Operação. }\end{array}$} & Sensibilização & 3,66 & \multirow{3}{*}{3,48} \\
\hline & & Local Descartes & 3,63 & \\
\hline & & Uso das TICs/EA & 3,16 & \\
\hline
\end{tabular}

Fonte: Elaborado pelos autores deste Trabalho, 2021.

Quadro 5 - Eixos estruturados-Síntese dos questionários PROFESSORES (Likert 1 a 5)

\begin{tabular}{|c|c|c|c|c|}
\hline Eixo Focado & $\begin{array}{c}\text { Descrição (Conteúdo) abordados } \\
\text { em escala Likert } 1 \text { a } 5\end{array}$ & Aspectos Chave & $\mathbf{R M}$ & $\begin{array}{l}\text { RM } \\
\text { Eixo }\end{array}$ \\
\hline $\begin{array}{ll}\text { Infraestrutura } & \text { da } \\
\text { Escola em TICs } & \end{array}$ & $\begin{array}{l}\text { Neste eixo, houve pergunta única } \\
\text { relacionada à Infraestrutura/TIC }\end{array}$ & $\begin{array}{l}\text { Infraestrutura } \\
\text { do } \\
\text { ensino/TICs }\end{array}$ & 3,25 & 3,25 \\
\hline \multirow{4}{*}{$\begin{array}{l}\text { Importância das TICs } \\
\text { Na melhoria de } \\
\text { aspectos da EA }\end{array}$} & \multirow{4}{*}{$\begin{array}{l}\text { Este eixo tem como proposta avaliar } \\
\text { às TICs na melhoria de aspectos da } \\
\text { EA }\end{array}$} & Conhecimento & 4,75 & \multirow{4}{*}{4,53} \\
\hline & & Habilidade & 4,41 & \\
\hline & & Atitudes & 4,67 & \\
\hline & & Valores Éticos & 4,58 & \\
\hline $\begin{array}{l}\text { Valor das TICs para a } \\
\text { EA em RS pelos } \\
\text { docentes }\end{array}$ & $\begin{array}{l}\text { Neste eixo, houve pergunta única } \\
\text { relacionada à concordância do uso das } \\
\text { TICs no apoio a EA em RS }\end{array}$ & $\begin{array}{l}\text { Valor do Apoio } \\
\text { à EA / RS com } \\
\text { TICs }\end{array}$ & 4,92 & 4,92 \\
\hline
\end{tabular}

Fonte: Elaborado pelos autores deste Trabalho, 2021. 
Quadro 6 Eixos estruturados - Síntese dos questionários PROFESSORES (MP)

\begin{tabular}{|c|c|c|c|c|}
\hline Eixo Focado & Descrição (Conteúdo) abordados & Aspectos Chave & $\begin{array}{l}\text { Escala } \\
\text { Usada }\end{array}$ & $\begin{array}{l}\text { RM } \\
\text { Eixo }\end{array}$ \\
\hline \multirow{4}{*}{$\begin{array}{l}\text { Status de Treinamento } \\
\text { em TICs }\end{array}$} & \multirow{4}{*}{$\begin{array}{l}\text { Neste eixo, houve pergunta única } \\
\text { relacionada à última vez que fez } \\
\text { cursos em informática e ensino com } \\
\text { uso das TICs }\end{array}$} & \multirow{4}{*}{\begin{tabular}{l|} 
Conhecimentos e \\
práticas no \\
ensino com TICs \\
pelos docentes
\end{tabular}} & RUIM-1 & \multirow{4}{*}{2,36} \\
\hline & & & REG-2 & \\
\hline & & & BOM-3 & \\
\hline & & & MB-4 & \\
\hline \multirow{3}{*}{$\begin{array}{l}\text { Status do Treinamento } \\
\text { em Resíduos Sólidos }\end{array}$} & \multirow{3}{*}{$\begin{array}{l}\text { Neste eixo, houve pergunta única } \\
\text { relacionada à capacitação em gestão } \\
\text { de resíduos sólidos aos docentes }\end{array}$} & \multirow{3}{*}{$\begin{array}{l}\text { Conhecimentos e } \\
\text { práticas no } \\
\text { ensino de RS }\end{array}$} & RUIM-1 & \multirow{3}{*}{1,39} \\
\hline & & & REG-2 & \\
\hline & & & BOM-3 & \\
\hline
\end{tabular}

Fonte: Elaborado pelos autores deste Trabalho, 2021.

E ao final o RM do eixo, a média aritmética do RM de todos os aspectos chaves de cada eixo focado, sintetizando a avaliação dos aspectos analisados em cada Eixo Focado (variável) em forma de indicador.

Nesta etapa, todos os indicadores de cada conjunto são normalizados e agregados em um único índice (CIFRIAN; ANDRES; VIGURI, 2015).

\subsection{AS VARIÁVEIS OBTIDAS PARA A ANÁLISE DE SWOT}

O termo SWOT é um acrônimo das palavras Strenghts (forças), Weaknesses (fraquezas), Opportunities (oportunidades) e Threats (ameaças). Neste trabalho, pretendeu-se avaliar os pontos fortes e frágeis para o desenvolvimento das práticas educativas socioambientais com o auxílio das TICs na instituição, sob a ótica da análise SWOT evidenciado neste estudo, como eles se relacionam e quais elementos podem ampliar suas forças e neutralizar as dificuldades encontradas, indicando sujeitos, recursos e ações que comporão diretrizes, o plano de trabalho estratégico condizente para seu melhor aproveitamento. Como essas forças são muito dinâmicas, suas constantes mudanças criam milhares de oportunidades e ameaças ou restrições para os administradores estratégicos (PEREIRA; ANTONIALLI, 2011). 
As variáveis (Forças, Fraquezas, Oportunidades e Ameaças) obtidas para a análise de SWOT, além das análises do contexto local e ambiente externo à instituição, foram levantadas por meio de questionários aplicados aos discentes e docentes. Buscou-se uma análise SWOT desenvolvida de maneira colaborativa, com diversidade de contribuições. O motivo de pesquisar dados em diversos agentes envolvidos nas amostras se deve a pretensão de entender o objeto de estudo através de uma perspectiva micro e macro (ARAÚJO; SCHWAMBORN, 2013).

Os questionários trabalhados com os pesquisados não focam diretamente a indicação das variáveis, tendo sido utilizado alguns métodos, primeiramente o procedimento do ranking médio (RM) realizados nos eixos focados (tópicos), qualificaram as variáveis estudadas nos questionários aplicados.

As análises buscam confrontar e reposicionar as indicações propostas pelos agentes mais atuantes no processo de aprendizado nos dados obtidos por questionários (docentes e discentes), permitindo-se obter uma visão imparcial da educação ambiental em gestão de resíduos sólidos na instituição de ensino com o apoio das TICs.

Existe uma boa distribuição qualitativa dos participantes na pesquisa aos docentes e discentes, com relação aos docentes, seis (6) lecionam na pós-graduação, onze (11) atuam na graduação, trinta e dois docentes (32) ministram aulas para alunos do ensino médio, sendo que dez (10) na área técnica profissionalizante de oficinas e laboratórios, nove (9) na área de ciências biológicas, cinco (5) na área de informática, e dois (2) na área de química, no total trinta e seis docentes que lecionam nestes diversos níveis. Quanto aos discentes respondentes, trinta e um (31) são do ensino médio, trinta e dois (32) da graduação e dez (10) da pós-graduação.

Adicionalmente, a base desses dados, são selecionadas no referencial teórico variáveis que representam os aspectos situacionais das práticas e políticas em 
resíduos sólidos no cenário brasileiro. As variáveis se apresentam como Forças e Fraquezas (Ambiente Interno) e das Oportunidades e Ameaças (Ambiente Externo).

Os dados obtidos foram alocados e analisados de acordo com dois ambientes, o interno e o externo, onde se tem como referencial o espaço de ensino formal e informal na instituição.

\subsubsection{AS VARIÁVEIS OBTIDAS NO AMBIENTE INTERNO}

Para o ambiente interno são indicados seis variáveis para a categoria Força e cinco para a categoria Fraqueza. Segundo Souto-Maior (2013), da análise do ambiente interno devem ser extraídos os principais pontos fortes e pontos fracos da organização. Quanto aos aspectos de recursos humanos relacionados às Forças são três variáveis, é destacado a competência técnica e excelência acadêmica da chefe da DISAI nesta reponsabilidade de promover ações neste campo educacional socioambiental, da mesma forma, dos professores pesquisados nas respectivas áreas acadêmicas e o manuseio e capacidade de aprendizado dos discentes com as TICs. Contudo, se destacam para as Fraquezas quatro variáveis: a necessidade de regularidade nos cursos de capacitação para ações pedagógicas utilizando as TICs, e em conhecimentos na gestão de resíduos sólidos necessários ao trabalho socioambiental na instituição, outra variável são as dúvidas dos discentes em EA de RS e por último a percepção dos Alunos das ações de sensibilização e EA em RS promovidas na IE.

No que diz respeito aos aspectos técnicos e gerenciais para o aprendizado aos discentes na temática resíduos sólidos, indicam-se como Forças três variáveis: a sinergia das TICs e o aprendizado EA em RS, capacidade das TICs em beneficiar aspectos da EA: Conhecimento/Habilidade/Atitudes/Valores Éticos, a infraestrutura da instituição em laboratórios e tecnologias e conteúdo em EA de RS em sites. Verificase como Fraqueza identificada, que as TICs podem ser 'inimigas' da sustentabilidade por meio da desinformação e as Fakes News.

RC: 89489

Disponível em: https://www.nucleodoconhecimento.com.br/engenharia-deproducao/tecnologias-da-informacao 


\subsubsection{AS VARIÁVEIS OBTIDAS NO AMBIENTE EXTERNO}

No ambiente externo são constatadas nove variáveis, sendo quatro como Oportunidades e cinco como Ameaças, fazendo-se de referências conceituais, humanas, sociais, técnicas, financeiras e legais. As variáveis, neste ambiente, são ainda subclassificadas dentro do ambiente operacional e geral.

Quadro 7 - Variáveis: Forças/Fraquezas (Interno) e Oportunidades/Ameaças (Externo)

\begin{tabular}{|c|c|}
\hline $\begin{array}{c}\text { Ambiente } \\
\text { Interno }\end{array}$ & $\begin{array}{l}\text { Ambiente } \\
\text { Externo }\end{array}$ \\
\hline Forças & Oportunidades (ambiente operacional) \\
\hline FO 1 - Prática nas TICs para aprendizados & $\begin{array}{l}\text { OP } 1 \text { - Plataformas digitais e App em EA } \\
\text { existentes }\end{array}$ \\
\hline FO 2 - Sinergia das TICs e o aprendizado & OP 2 - Formação continuada \\
\hline EA em RS & Docentes/TIC/RS \\
\hline FO 3 - Importância do apoio das TICs em aspectos & OP 3 - MMA \\
\hline da EA: Conhecimento/Habilidade/Atitudes/Valores & Oportunidades (ambiente geral) \\
\hline Éticos & OP 4 - Legislações das temáticas \\
\hline FO 4 - Infraestrutura da Escola em TIC/Sites/ & socioambientais OP 4 - Políticas \\
\hline EA em RS & ex1stentes(PNRS;PNEA;ODS) \\
\hline $\begin{array}{l}\text { FO } 5 \text { - Os docentes/Valor do Apoio à EA / RS } \\
\text { com TIC }\end{array}$ & \\
\hline $\begin{array}{l}\text { FO } 6 \text { - DISAI/ competência técnica/excelência } \\
\text { acadêmica }\end{array}$ & \\
\hline Fraquezas & Ameaças (ambiente operacional) \\
\hline FR 1 - Dúvidas dos discentes em EA de RS & AM 1 - Pouca execução da coleta seletiva municipa \\
\hline FR 2 - Status de Treinamento em & Ameaças (ambiente geral) \\
\hline TIC/Docentes & AM 2 - Deficiencia na coleta de RS \\
\hline FR 3 - Status do Treinamento em & AM 3 - Baixa massa coletada de resíduos \\
\hline RS/Docentes & recicláveis \\
\hline FR 4 - Percepção dos Alunos das ações de & AM 4 - Pouca percepção às questões \\
\hline sensibilização e EA em RS promovidas na IE & socioambientais \\
\hline $\begin{array}{l}\text { FR } 5 \text { - As TICs podem ser 'inimigas' da } \\
\text { sustentabilidade por meio da desinformacão e Fake }\end{array}$ & AM 5 - Irregularidade informacional dos \\
\hline News & reciclaxeis \\
\hline
\end{tabular}

Fonte: Elaborado pelos autores deste Trabalho, 2021.

As Oportunidades apontadas que fazem parte do ambiente operacional: As Plataformas e App em EA existentes; por ser uma responsabilidade compartilhada da

RC: 89489

Disponível em: https://www.nucleodoconhecimento.com.br/engenharia-deproducao/tecnologias-da-informacao 
sociedade, identifica-se como variável, a formação continuada sugerida aos docentes no ensino com as TICs e a capacitação em resíduos sólidos como mencionado na PNRS (Política Nacional de Resíduos Sólidos).Outra variável externa operacional à instituição pública de ensino (IE) estudada é a atuação do Ministério do Meio Ambiente (MMA), como uma gerência específica para a operacionalização das temáticas socioambientais comprovada por sua própria existência.

Adicionalmente às variáveis oportunidades, se adequam ao ambiente geral, legislações das temáticas socioambientais e as políticas públicas existentes. No quadro 7 , encontram-se, resumidamente, todas as variáveis consideradas, organizadas nos Ambientes Interno (Forças e Fraquezas) e externo (Oportunidades e Ameaças).

Quanto às Ameaças para o ambiente geral, é apontada a deficiência entre os setores da sociedade na coleta de resíduos sólidos, segundo o Instituto Brasileiro de Geografia e Estatística (IBGE), mais de 20 milhões de pessoas no Brasil não têm acesso a nenhum tipo de serviço de coleta de lixo (IBGE, 2019).

Foi identificado baixa massa coletada de resíduos recicláveis relatado no Diagnóstico do Manejo de Resíduos Sólidos Urbanos (2017) que indicam 4\% de massa coletada reciclável (SNIS, 2019).

\subsection{COMENTÁRIOS SOBRE AS VARIÁVEIS OBTIDAS}

A partir dos resultados é possível ter uma visão dos pontos em potenciais e dos pontos que se neutralizam, essenciais para se traçar estratégias adequadas a cada situação.

\subsubsection{FORÇAS}

Observa-se que as variáveis indicadas nessa categoria concentram seus pontos fortes na interatividade dos agentes participantes dos processos educativos socioambientais com o apoio das TICs, bem como no desenvolvimento desses.

RC: 89489

Disponível em: https://www.nucleodoconhecimento.com.br/engenharia-deproducao/tecnologias-da-informacao 
A premissa de termos pessoas que estão estimuladas a desenvolver alguma ação ou propostas de aprendizado na temática resíduos sólidos com o apoio das TICs, não necessariamente indica uma resposta positiva ao trabalho a ser desenvolvido, embora, a existência dessas circunstâncias facilita a concretização do objetivo proposto em questão.

A reflexão que se faz é o modo como esses processos ocorrem e como os participantes nos processos educativos socioambientais de fato realizam suas ações de forma a viabilizá-los.

Os alunos, professores e gestores presentes nas situações são motivados com suas atividades, o funcionamento da DISAI e a situação organizacional engajada e alinhada as propostas socioambientais do MMA para as instituições públicas de ensino são favoráveis para a implantação de atividades educacionais ambientais previstas com auxílio das TICs.

Essas características contribuem para a consolidação da Educação Ambiental em resíduos sólidos e devem ser potencializadas pelas oportunidades identificadas para melhorar o processo educativo, tornando-o pleno dentro e fora da instituição. No entanto, a deficiência observada na contemplação dos objetivos muito se relaciona com as limitações enfatizadas pelas fraquezas e as ameaças encontradas.

\subsubsection{FRAQUEZAS}

As fraquezas apontadas mostram um reflexo das dificuldades internas para o trabalho da Educação Ambiental em resíduos sólidos utilizando as TICs. Percebe-se que a maior parte das variáveis apontadas se relacionam, sugerindo uma preocupação de correlação no planejamento das ações que as suprirão.

A própria análise deste, já se remete a necessidade do trabalho coletivo, ou seja, o sucesso da aplicação e implantação dos temas e ações socioambientais na temática

RC: 89489

Disponível em: https://www.nucleodoconhecimento.com.br/engenharia-deproducao/tecnologias-da-informacao 
resíduos sólidos é de responsabilidade de todos que fazem parte da escola. Assim, a capacitação dos docentes, a inclusão digital e a importância dada à temática socioambiental previstas no PRS colocam a escola em um patamar alto de envolvimento.

No que diz respeito aos sujeitos do ambiente escolar, implica no direcionamento que a instituição necessita estabelecer, envolvendo todo o corpo docente e discente, sendo pertinente colocar as indagações relacionadas ao conteúdo e domínio das temáticas socioambientais em resíduos sólidos e como estas serão desenvolvidas, em uma posição direta dos processos educativos ambientais, também com o apoio das TICs.

\subsubsection{OPORTUNIDADES}

As oportunidades apresentam perspectivas operacionais contundentes para 0 aproveitamento da Educação Ambiental com o apoio das TICs na Instituição de Ensino. Ainda de acordo com Oliveira (2011), as oportunidades são as forças ambientais incontroláveis pela empresa, que podem favorecer sua ação estratégica, desde que conhecidas e aproveitadas satisfatoriamente enquanto perduram.

A criação de um aplicativo (app) para celular é um projeto educativo e de comunicação, que visa à propagação de informações, e se apresenta como uma ferramenta poderosa para auxiliar na educação ambiental em resíduos sólidos aos discentes na instituição de ensino e fora dela.

Viabilizando caminhos educativos nesta temática para uma vida mais sustentável, o que é uma obrigatoriedade como está disposto em lei, ou seja, é necessário que se tenha "[...] programas e ações de educação ambiental que promovam a não geração, a redução, a reutilização, a coleta seletiva e a reciclagem de resíduos sólidos [...]" (BRASIL, 2010).

RC: 89489

Disponível em: https://www.nucleodoconhecimento.com.br/engenharia-deproducao/tecnologias-da-informacao 
O desenvolvimento de benchmarking, é um importante modo de se desenvolver melhores práticas e criação destas tecnologias, em parcerias publicas privadas, pois já existem, por exemplo, diversos Apps com a finalidade de coleta seletiva de resíduos sólidos no mercado.

Com intuito de auxiliar no ensino de temas ambientais, o Ministério do Meio Ambiente (MMA) vem trabalhando na plataforma digital de ensino a distância (EAD), com cursos que têm por objetivo instruir diversos públicos na importante temática ambiental, qualificar a gestão de resíduos sólidos promovendo a capacitação de gestores públicos e atores estratégicos da sociedade civil organizada com base na Estratégia Nacional de Educação Ambiental e Comunicação Social para a Gestão de Resíduos Sólidos (Educares) (BRASIL MMA, 2019).

A Estratégia Nacional de Educação Ambiental (EA) e Comunicação Social (CS) na Gestão de Resíduos Sólidos - Educares é uma iniciativa do Departamento de Educação Ambiental (DEA), da Secretaria de Articulação Institucional e Cidadania Ambiental (SAIC), do Ministério do Meio Ambiente (MMA) (BRASIL MMA, 2019).

Aumenta-se assim, os incentivos para os docentes buscarem capacitação e aperfeiçoamento nas áreas relacionadas ao gerenciamento de resíduos sólidos (BRASIL MMA, 2019).

Nota-se que as variáveis vistas do ponto de vista operacional, apresentam ainda tendências positivas quando amparadas e apoiadas pelas variáveis do ambiente geral.

As políticas públicas existentes são bem definidas, apresentam leis e programas marcantes. 


\subsubsection{AMEAÇAS}

Na prática, apenas $17 \%$ da população do país é atendida pela coleta seletiva, de acordo com um relatório de 2018 da ONG Compromisso Empresarial de Reciclagem (CEMPRE) (CICLOSOFT, 2018).

Tornando esta variável do ambiente externo operacional alarmante. Dentre as razões que dificultam a reversão desse cenário, chama a atenção que um dos principais empecilhos seja a falta de informação da população.

A irregularidade informacional dos materiais recicláveis e a pouca percepção às questões socioambientais, são outras duas variáveis observadas na sociedade sinalizadas como Ameaças para o ambiente geral.

Uma pesquisa do lbope de 2018 mostra que 66\% da população sabe pouco ou nada sobre coleta seletiva, $66 \%$ dos brasileiros afirmam saber pouco ou nada a respeito de coleta seletiva e $28 \%$ não sabem identificar as cores das lixeiras para coleta do material e 39\% não separam o lixo (IBOPE, 2018).

Outro levantamento, este de 2019 feito pelo instituto Ipsos, revelou que 54\% dos brasileiros não entendem como funciona a reciclagem em sua região.

A pesquisa também verificou quem acreditava que todos os plásticos podem ser reciclados, o que é um equívoco, já que alguns tipos do material não podem ser reaproveitados, $55 \%$ dos entrevistados globalmente e $65 \%$ no Brasil concordaram com a afirmação (PESSINI, 2019).

Observa-se que tais variáveis que contemplam elementos que trazem impactos socioambientais, dependem de um plano de gestão em educação ambiental de resíduos sólidos que atendam às necessidades perceptivas e informacionais da sociedade.

RC: 89489

Disponível em: https://www.nucleodoconhecimento.com.br/engenharia-deproducao/tecnologias-da-informacao 


\subsection{RECOMENDAÇÕES DE USO DAS TIC}

Entre as TICs sugeridas na pesquisa com os docentes, foram respondidas pelos professores trezentas recomendações de uso das TICs entre as apresentadas, para apoio e potenciais ferramentas no ensino da temática resíduos sólidos (RS) na escola, em suas modalidades de ensino.

Figura 2 - Distribuição de frequências de preferencias das TICs pelos docentes

\begin{tabular}{|c|c|c|c|c|}
\hline \multicolumn{5}{|c|}{ Distribuição de frequências de preferencias das TICs em ordem crescente. } \\
\hline & \multicolumn{2}{|c|}{ Frequências Simples } & \multicolumn{2}{|c|}{ Frequências Acumuladas } \\
\hline & & & Frequência & Frequência \\
\hline & Frequência & Frequência & Absoluta & Relativa \\
\hline TICs & Absoluta & $\begin{array}{c}\text { Relativa } \\
(\%)\end{array}$ & $\begin{array}{c}\text { Acumulad } \\
\mathbf{a} \\
\end{array}$ & $\begin{array}{c}\text { Acumulada } \\
(\%)\end{array}$ \\
\hline Facebook & 8 & 2,67 & 8 & 2,67 \\
\hline Arquivos em áudio & 9 & 3 & 17 & 5,67 \\
\hline Google & 12 & 4 & 29 & 9,67 \\
\hline Localização GPS & 14 & 4,67 & 43 & 14,34 \\
\hline WhatsApp & 15 & 5 & 58 & 19,34 \\
\hline Imagens (Fotos) & 16 & 5,33 & 74 & 24,67 \\
\hline Endereços-Link & 16 & 5,33 & 90 & 30 \\
\hline QR Codes - Mídias & 16 & 5,33 & 106 & 35,33 \\
\hline Computador (PC) & 18 & 6 & 124 & 41,33 \\
\hline Xou Tube & 20 & 6,7 & 144 & 48,03 \\
\hline Datashow & 21 & 7 & 165 & 55,03 \\
\hline Aplicativos Educacionais & 21 & 7 & 186 & 62,03 \\
\hline Notebook & 22 & 7,33 & 208 & 69,36 \\
\hline Sites educacionais & 22 & 7,33 & 230 & 76,69 \\
\hline Jogos educacionais & 22 & 7,33 & 252 & 84,02 \\
\hline Smartphone & 23 & 7,7 & 275 & 91,72 \\
\hline Vídeos & 25 & 8,3 & 300 & 100,0 \\
\hline Total & 300 & 100,0 & --- & --- \\
\hline
\end{tabular}

Fonte: Elaborado pelos autores deste Trabalho, 2021.

RC: 89489

Disponível em: https://www.nucleodoconhecimento.com.br/engenharia-deproducao/tecnologias-da-informacao 
Sendo obtido o conjunto de frequências absolutas para as TICs elencadas como produtivas neste ensino na temática de RS, ordenados os dados do menor para o maior, formou-se o rol de dados (Figura 2).

\section{PROPOSTA DE EA EM RS COM APOIO DA TIC}

Propor as TICs no apoio à educação ambiental em resíduos sólidos, mais sugeridas pelo estudo teórico e na pesquisa com os docentes, como solução às lacunas existentes das práticas e conhecimentos ambientais em gestão de resíduos sólidos pelos discentes, nunca foi um objetivo fundamental deste estudo, pois o fato da simples apresentação das TICs com maior potencial e utilização na educação ambiental de resíduos sólidos na instituição, pode gerar uma insatisfação, por aparentar falta de completude e indicação nas ações de apoio na aprendizagem com as TICs .

Não se trata de compreender a tecnologia como ferramenta didática, mas como um mundo interativo integrante no dia a dia das pessoas (MARCHIORATO, 2018).

Para tanto, a integração destas tecnologias digitais na educação precisa ser pensada de forma crítica e criativa, desenvolvendo autonomia e reflexão dos envolvidos, e proporcionando diferentes possibilidades de ensino (GASPI; MAGALHÃES JÚNIOR, 2018).

Os recursos educacionais estão disponíveis, mas é preciso inseri-los na rotina acadêmica com ações práticas, flexíveis, de forma integrada, a fim de tornar a sala de aula uma combinação de espaços, ferramentas e estilos de aprendizagem, objetivando o desenvolvimento do aluno (OLIVEIRA, 2019).

Uma das consequências destes recursos digitais para este estudo, é encontrar um espaço de convergência das tecnologias e melhoria da qualidade nos processos de educação ambiental em resíduos sólidos.

RC: 89489

Disponível em: https://www.nucleodoconhecimento.com.br/engenharia-deproducao/tecnologias-da-informacao 
Entre as diversas ações realizadas pela divisão de sustentabilidade ambiental (DISAl) na instituição de ensino, a informação ambiental é também relatada por um canal virtual, o painel da sustentabilidade, chamado Web Site 'CEFET SUSTENTÁVEL'; onde são descritas atividades e legislações com o intuito de informar, gerar conhecimento, engajar a comunidade no contexto de eixos diversos da sustentabilidade ambiental.

Este painel digital vem ao encontro de alguns objetivos desta pesquisa, porém, almeja- se ao final deste estudo, que o site ou painel seja potencializado e reposicionado como portal virtual de referência, ancorando e promovendo com as TICs adequadas, novos procedimentos orientativos e didáticos, direcionados à educação ambiental da temática de resíduos sólidos à instituição de ensino.

Devendo assim, ser dinamizado como instrumento virtual, possuindo ferramentas que construam um real relacionamento entre quem produz e quem consome a informação.

Para o autor Rodrigues (2006, p. 94), o portal não é um site ampliado.

A diferença entre site e portal é que o portal tem do foco no seu público e cria conteúdo específicos para eles, os chamados conteúdos verticais, complementa o autor:

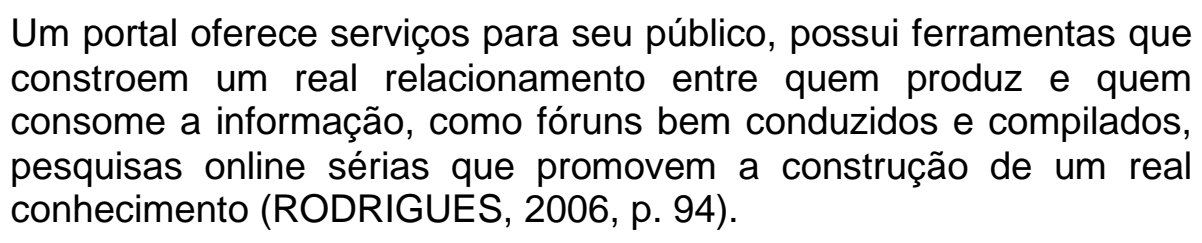

Muito mais que uma peça tecnológica, um repositório institucional se constitui hoje, no contexto de um amplo e crescente movimento internacional de apoio ao livre acesso à informação científica, num ator político (RIEGER, 2008).

Consolida-se assim, a viabilização da proposta de sistematização das TICs ancoradas no painel existente, "Site Sustentável", sendo reconstruído, repaginado e renomeado como um "Portal Virtual de Referência" na área de educação ambiental cotidiana da

RC: 89489

Disponível em: https://www.nucleodoconhecimento.com.br/engenharia-deproducao/tecnologias-da-informacao 
temática de resíduos sólidos; ou de forma independente, na construção de um "Portal Temático".

O Portal de Referência a ser utilizado, faz o papel de um espaço de referência digital, tanto das atividades educacionais formais, como informais aos discentes na instituição.

São apresentadas, estratégias de metodologias de aprendizagem ambiental em RS combinadas com determinadas TICs, incluídas nessa proposta: 0 aplicativo institucional de descarte seletivo, peças publicitárias educacionais ambientais em RS com QR CODE e os links com as sequências didáticas na temática resíduos sólidos elaboradas coletivamente por professores, de forma interdisciplinar, na instituição de ensino (Figura 3).

O objetivo das Sequencias Didáticas nas páginas do site sustentável institucional é disponibilizar aos professores uma metodologia de trabalho envolvendo a temática dos Resíduos Sólidos-RS por meio de aulas dinâmicas com diversos tipos de instrumentos didáticos apoiado pelas TICs para que a aprendizagem ocorra de forma significativa.

Desta forma, o professor e o aluno poderão acessar na plataforma digital institucional a Sequência Didática (SD), e abordar os conceitos em torno de um tema gerador de conhecimento "Gestão e Gerenciamento de Resíduos Sólidos", que tem como meta apresentar aos discentes o problema enfrentado por nossa sociedade, face a quantidade de resíduos sólidos que são diariamente gerados, seus impactos no ambiente e como este problema pode ser minimizado a partir de um consumo consciente.

RC: 89489

Disponível em: https://www.nucleodoconhecimento.com.br/engenharia-deproducao/tecnologias-da-informacao 
Figura 3 - As TICs propostas organizadas no portal de sustentabilidade

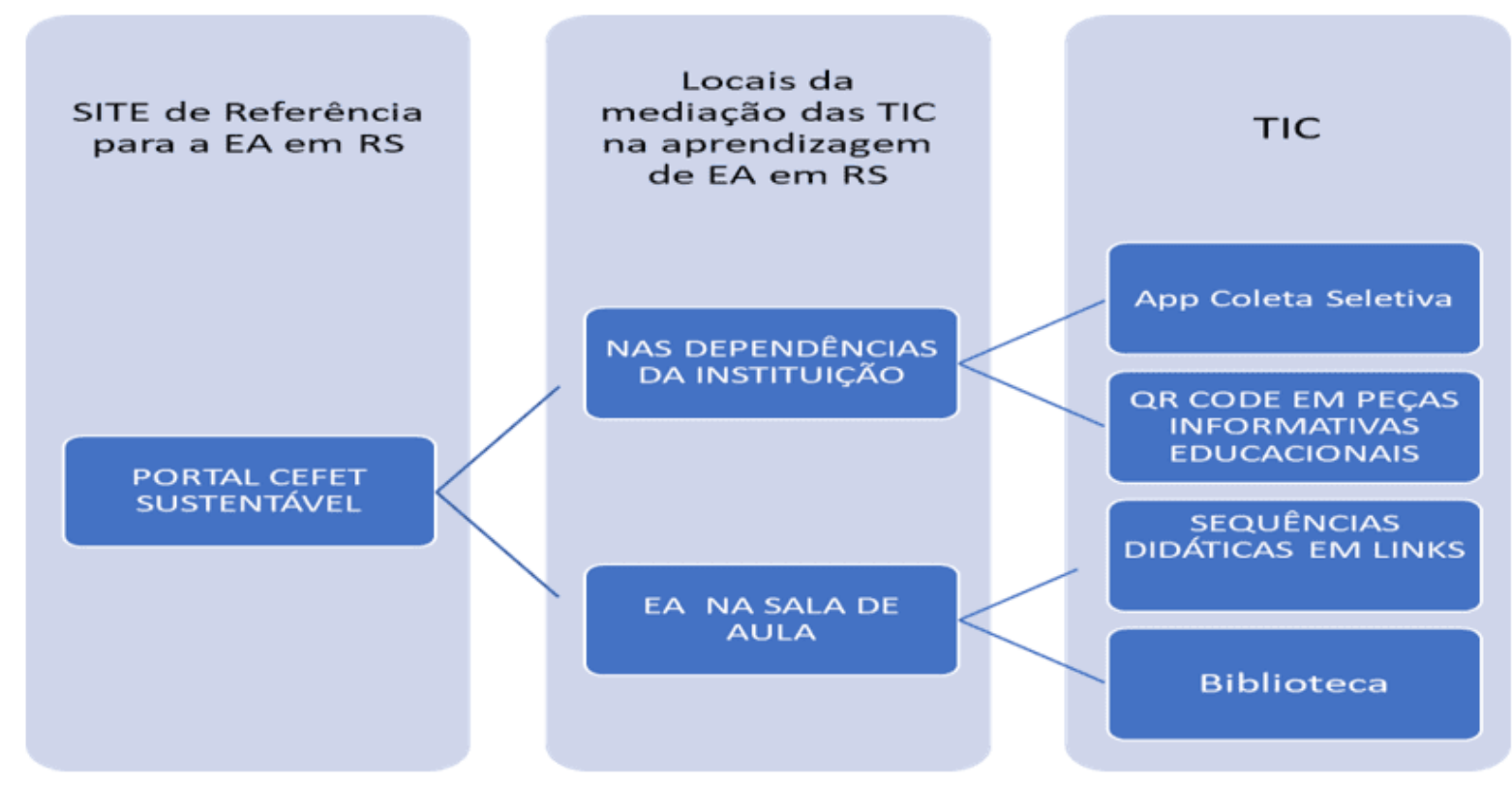

Fonte: Adaptado do trabalho de Moran (2001)

As TICs estão organizadas no portal de sustentabilidade institucional 'CEFET SUSTENTÁVEL', como elemento integrador e catalizador de todo o processo de EA em RS na IE com o apoio das TICs, indicado neste estudo, como site de referência (MORAN, 2001).

As diversas metodologias ativas de aprendizagem disponíveis podem ser combinadas, integradas e utilizadas, em todos os níveis de ensino, buscando otimizar o aprendizado discente e viabilizar a abordagem dos conteúdos, nas diversas áreas do conhecimento (ALVES et al., 2020).

Destarte, a proposta do portal de referência cumpre com o papel de subsidiar as ações educacionais ambientais da temática resíduos sólidos aos discentes na instituição de ensino, da seguinte forma (Quadro 8).

As diferentes ações promovidas pelos gestores da instituição e os professores, são inseridas nas respectivas categorias, de ensino formal e informal, da educação RC: 89489

Disponível em: https://www.nucleodoconhecimento.com.br/engenharia-deproducao/tecnologias-da-informacao 
ambiental da temática resíduos sólidos. Sendo uma metodologia dinâmica, o mapa está sujeito a variações ao longo do tempo.

Quadro 8 - TICs e diretrizes no apoio à EA de RS aos discentes da IE

\begin{tabular}{|l|l|}
\hline $\begin{array}{l}\text { Interdisciplinarmente } \\
\text { na educação formal }\end{array}$ & a) $\begin{array}{l}\text { Recebendo em suas páginas digitais o planejamento de atividades e } \\
\text { materiais em bibliotecas, com apoio das TICs, através da uma } \\
\text { sequência com procedimentos didático-metodológicos, utilizando } \\
\text { artefatos tecnológicos e mídias. }\end{array}$ \\
\hline b) No SITE de referência, na adequação da utilização das TIC nas \\
diversas ações de sensibilização institucional promovidas pela \\
DISAI, como por exemplo, vídeos e podcasts explicativos do \\
cotidiano e a gestão de resíduos;
\end{tabular}

Fonte: Elaborado pelos autores deste Trabalho, 2021.

Ao apresentar e sistematizar elementos das tecnologias da informação e comunicação, almeja-se a melhoria, a qualidade, nos processos formais e informais de educação ambiental na temática resíduos sólidos atualmente executados na instituição de ensino.

A Gestão Ambiental traduz-se na realização de atividades propensas a obter efeitos positivos sobre o meio ambiente, minimizando e/ou eliminando os danos causados pela intervenção humana, sempre numa óptica de melhoria contínua (NOBRE, 2010).

\section{CONSIDERAÇÕES FINAIS}

A metodologia de estudo desenvolvida na temática dos resíduos sólidos, logrou-se como caminho, a criação de indicadores oriundos da síntese dos questionários aplicados aos discentes e docentes; das análises através da literatura; e da

RC: 89489

Disponível em: https://www.nucleodoconhecimento.com.br/engenharia-deproducao/tecnologias-da-informacao 
construção da matriz SWOT. Esses viabilizaram a construção da proposta do uso das TICs neste aprendizado.

As análises das variáveis forças e fraquezas do ambiente interno institucional, das oportunidades e ameaças no ambiente externo, permitem observar que a identificação destes parâmetros e as mudanças promovidas por ações educacionais ambientais sustentáveis com usos das TICs no aprendizado formal e informal da temática resíduos sólidos, sendo refletidas tanto no ambiente interno, quanto no externo institucional.

No nível organizacional, ou seja, no ambiente interno institucional público de ensino, ocorre uma sinergia educacional nesta temática de resíduos sólidos, a redução de custos e riscos e, no futuro, inovação e reposicionamento institucional de ensino.

No ambiente externo, inicialmente, as oportunidades (ambiente operacional) são bem aproveitadas gerando e reputação e legitimidade de suas ações e, no futuro é um caminho para a minoração das ameaças (ambiente operacional e geral) e um norte para a trajetória do crescimento sustentável ambiental na temática resíduos sólidos da sociedade.

Ressalta-se que, ao observar neste estudo a proposta das TICs organizadas no portal de sustentabilidade institucional, reforça-se principalmente a Responsabilidade Social, fortalecendo o início de uma atualização do modelo de gestão de uma instituição de ensino. Nesta perspectiva, atende-se um dos pilares sobre os quais a Instituição de Ensino Federal se edifica no contexto regional em que se coloca, tendo em vista a formação humanística; a ética dos estudantes; a relação da produção de seu conhecimento ambiental em resíduos sólidos no âmbito local e global com os usos das TICs; a sustentabilidade ambiental como fator transversal; e a cultura como propriedade inerente à promoção de mudanças estruturais na sociedade na temática gerenciamento e gestão de resíduos sólidos.

RC: 89489

Disponível em: https://www.nucleodoconhecimento.com.br/engenharia-deproducao/tecnologias-da-informacao 
A educação ambiental sempre foi preconizada como instrumento para a transformação da sociedade, pretende-se com a contribuição deste estudo, que as peculiaridades e práticas da legislação, nesta temática de resíduos sólidos, tenha suas explicações e o alcance comunicativo ampliados com os usos das tecnologias da informação e comunicação; que a proposta e suas diretrizes permitam facilitar o entendimento do tema central das leis e resoluções, salientando para quem estas orientações devem ser dirigidas; destacando quais são os benefícios e as utilidades destas orientações estabelecidas. As diversas legislações ambientais existentes e suas vertentes, se apresentam como um divisor de águas e porto seguro em direcionar comportamentos em relação a temática dos resíduos sólidos. Devendo assim, serem tratadas como algo a ser disponibilizado digitalmente e que deve ser facilitado a compreensão e o entendimento, estabelecendo novas relações entre as informações, e incentivando os conhecimentos sistematizados pois, em toda parte, existem pessoas ansiosas em praticar as metodologias assertivas a favor do meio ambiente sustentável. Abre-se neste estudo uma provocação, o apoio de um cenário tecnológico informacional temático, mediação esta, que viabiliza aos stakeholders da instituição de ensino, trilhar coletivamente novos caminhos, germinando um relacionamento preferível com o ensino ambiental e a sensibilização da temática resíduos sólidos, sempre permitindo ser estudada na melhor perspectiva, prospectando boa vontade e a mente aberta para os aprendizados de todos os discentes da instituição nestes estudos.

\section{REFERÊNCIAS}

AAKER, David.; KUMAR, V.; DAY, G. Marketing research. John Wiley \& Sons, 1995. ALBANO, L. B.; SCOTON, E. J.; BATTISTELLE, R. A. G. Diagnóstico dos resíduos sólidos urbanos no Brasil após a política nacional dos resíduos sólidos a partir de dados do SNIS. In: CONGRESSO SUL-AMERICANO DE RESÍDUOS SÓLIDOS E 
SUSTENTABILIDADE - CONRESOL, 1., 2018, Gramado, RS. Anais ... Gramado, RS: Instituto Brasileiro de Estudos Ambientais, 2018.

ALVES, D. de S.; SILVA, F. V. V.; LIMA, R. L. F. de A.; RIBEIRO, E. M. S. Interações ecológicas na Caatinga: uma proposta de sequência didática utilizando seminários e o aplicativo Kahoot. Revista Brasileira de Educação Ambiental (RevBEA), v. 15, n. 6, p. 133-153, 28 nov. 2020.

ARAÚJO, Kássia Karina; PIMENTEL, Angélica Kelly. A problemática do descarte irregular dos resíduos sólidos urbanos nos bairros Vergel do Lago e Jatiúca em Maceió, Alagoas.

Revista Gestão \& Sustentabilidade Ambiental, v. 4, n. 2, p. 626-668, out. 2015. doi:http://dx.doi.org/10.19177/rgsa.v4e22015626-668.

ARAÚJO, Marcelino Gomes de; SCHWAMBORN, Silvia Helena Lima. A Educação Ambiental em análise SWOT. Ambiente \& Educação, v. 18, n. 2, p. 183-208, 2013.

ASSAD, Leonor. Apresentação - lixo: uma ressignificação necessária. Cienc. Cult., São Paulo, v. 68, n. 4, p. 22-24, Dec. 2016. http://dx.doi.org/10.21800/231766602016000400009 .

BARROSO-OSUNA, J.; GUTIÉRREZ-CASTILLO, J.; LLORENTE-CEJUDO, M.;

VALENCIA ORTIZ, R. Difficulties in the Incorporation of Augmented Reality in University Education: Visions from the Experts. Journal of New Approaches in Educational Research, v. 8, n. 2, p. 126-141, july 2019. doi:http://dx.doi.org/10.7821/naer.2019.7.409.

BRANDALISE, Mary Ângela Teixeira. Tecnologias De Informação E Comunicação Nas Escolas Públicas Paranaenses: Avaliação De Uma Política Educacional Em Ação. Educ. rev., Belo Horizonte,v.35, e 
206349,

$<$ http://www.SciELO.br/Sci-

ELO.php?script=sci_arttext\&pid=S010246982019000100412\&lng=en\&nrm=iso $>$ acce ss on June 27, 2019. https://doi.org/10.1590/01024698206349.

BRASIL. Lei n. 9.795/1999. Dispõe sobre a Educação Ambiental, institui a Política Nacional de Educação Ambiental e dá outras providências. Disponível em: http://www.lei.adv.br/9795- 99.htm. Acesso em: 20 out 2019.

BRASIL. Lei $\mathbf{1 2 . 3 0 5}$ de 2 de agosto de 2010. Institui a Política Nacional de Resíduos Sólidos; altera a Lei no 9.605, de 12 de fevereiro de 1998; e dá outras providências.Disponível em: http://www.planalto.gov.br/ccivil_03/_Ato20072010/2010/Lei/L12305.htm. Acesso em: 20 jul. 2019.

BRASIL. Ministério do Meio Ambiente. Secretaria de Articulação Institucional e Cidadania Ambiental. Departamento de Educação Ambiental. Educares - Educação Ambiental na Gestão de Resíduos Sólidos - Turma 5. 2019. Disponível em: https://ead.mma.gov.br/course/info.php?id=269.Acesso em: 21 dez. 2019.

BRINGHENTI, J. R.; BASSANI, P. D.; LAIGNIER, I. T. R.; BRAGA, F. S.; GÜNTHER, W.R. Coleta seletiva em condomínios residenciais verticalizados do município de Vitória (ES): características operacionais e de participação social. urbe, Rev. Bras. Gest. Urbana, Curitiba, v.11, e20170223, 2019. https://doi.org/10.1590/21753369.011.e20170223.

BUCHANAN, J.; PRESSICK-KILBORN, K.; MAHER, D. Promoção da educação ambiental para alunos em idade escolar que usam tecnologias digitais. Eurasia Journal of Mathematics, Science and Technology Education, v. 15, n. 2, 2019. https://doi.org/10.29333/ejmste/100639.

CABERO-ALMENARA, J.; BARROSO-OSUNA, J.; LLORENTE-CEJUDO, C.; 
FERNÁNDEZ MARTÍNEZ, M. M. Augmented Reality (AR) Educational Uses: Experiences in Educational Sciences. Sustainability, 11, 4990, 2019.

CAFURE, V. A; PATRIARCHA-GRACIOLLI, S. R. Os resíduos de serviço de saúde e seus impactos ambientais: uma revisão bibliográfica. Interações, Campo Grande, v. 16, n. 2, p.301-314, dez. 2015.

CAMILLERI, M. A.; CAMILLERI, A.C. Digital Learning Resources and Ubiquitous Technologies in Education. Tech Know Learn, v. 22, p. 65-82, 2017. https://doiorg.ez24.periodicos-.capes.gov.br/10.1007/s10758-016-9287-7

CARLI, A. A. de. A Água e seus Instrumentos de Efetividade: educação ambiental, normatização, tecnologia e tributação. São Paulo: Millennium, 2013.

CARVALHO, C. R. As tecnologias móveis na escola e o trabalho docente: as contribuições de uma pesquisa intervenção na formação continuada de professores da educação básica.2017. Tese (Doutorado) - Universidade Estadual Paulista (UNESP), Faculdade de Ciências e Tecnologia, Presidente Prudente, 2017.

CARVALHO, Wander Guilherme Rocha; ARAÚJO, José Augusto Faria de. Mídias locativas e realidade aumentada: potencialidades para o ensino geografia na cibercultura. Para Onde!?,Porto Alegre, RS, v. 10, n. 1, p. 83-89, set. 2018. doi:https://doi.org/10.22456/1982-0003.85597.

CEBRIÁN G.; JUNYENT, M. Competencies in Education for Sustainable Development: Exploring the Student Teachers' Views. Sustainability, v. 7, n. 3, p. 2768-2786, 2015.

CENTRO FEDERAL DE EDUCAÇÃO TECNOLÓGICA CELSO SUCKOW DA

FONSECA - CEFET/RJ. Plano de Desenvolvimento Institucional (PDI) 2015-2019. Rio de Janeiro, 2015.

RC: 89489

Disponível em: https://www.nucleodoconhecimento.com.br/engenharia-deproducao/tecnologias-da-informacao 
CICLOSOFT. Compromisso empresarial para a reciclagem. 2018. Disponível em: http://cempre.org.br/ciclosoft/id/9. Acesso em: 10 jan. 2020.

CIFRIAN, Eva; ANDRES, Ana; VIGURI, Javier R. Desenvolvimento de um sistema regional de informação ambiental com base em indicadores de resíduos em nível macro. Ecological Indicators, v. 53, p. 258-270, 2015.

CLEMENT, J. Number of global social media users 2010-2021. Statista. 14 Aug. 2019. Disponível em: https://shoptech.media/wp-content/uploads/2019/10/number-ofworldwide- social-network-users. Acesso em: 20 mar. 2020.

CORRÊA,L. A. Comércio e meio ambiente : atuação diplomática brasileira em relação ao selo verde. Brasília: Instituto Rio Branco; Fundação Alexandre de Gusmão, 1998.

DANIELA, L.; VISVIZI, A.; GUTIÉRREZ-BRAOJOS, C.; LYTRAS, M. D. Sustainable Higher Education and Technology-Enhanced Learning (TEL). Sustainability, 10, 3883, 2018.

DEMOLY, Karla Rosane do Amaral; SANTOS, Joceilma Sales Biziu dos. Aprendizagem, educação ambiental e escola: modos de en-agir na experiência de estudantes e professores. Ambient. soc., São Paulo, v. 21, e00872, 2018. https://doi.org/10.1590/18094422asoc0087r2vu18l1ao.

ESPINOSA, D. C. R.; SILVAS, F. P. C. Resíduos sólidos: abordagem e tratamento. In: PHILIPPI-JR, A.; ROMÉRO, M. de A.; BRUNA, G. C. (Ed.). Curso de Gestão Ambiental. São Paulo: Manole, 2014. 1245 pág.

FARRELLY, Glen. Which way is up? How locative media may enhance sense of place. International Journal of Mobile Human Computer Interaction, IGI Global, v. 7, n. 3, p. 55-66, July 2015.

RC: 89489

Disponível em: https://www.nucleodoconhecimento.com.br/engenharia-deproducao/tecnologias-da-informacao 
FLICK, Uwe. Uma Introdução à Pesquisa Qualitativa. Porto Alegre: Bookman, 2004.

GARCIA, J. M. S. Realidad aumentada: tecnologia para la formacion. Pixel-Bit. Revista de Medios y Educacion, n. 49, p. 241-243, 2016.

GIL, Antônio Carlos. Como elaborar projetos de pesquisa. 4. ed. São Paulo: Atlas, 2009.

GOBIRA, A.; CASTILHO, R.; VASCONCELOS, F. Contribuições da Educação Ambiental na Política Nacional de Resíduos Sólidos. Revista Eletrônica do Mestrado em Educação Ambiental, v. 34, n.1, p. 57-71, 2017.

GREENHOW, C.; ASKARI, E. Learning and teaching with social network sites: a decade of research in K-12 related education. Educ Inf Technol, v. 22, p. 623-645, 2017. https://doi.org.ez24.periodicos.capes.gov.br/10.1007/s10639-015-9446-9

GU, L.L.; SKIERKOWSKI, D.; FLORIN, P.; FRIEND, K.; YI, Y. Computers in human behavior Facebook, Twitter, and Qr codes: an exploratory trial examining the feasibility of social media mechanisms for sample recruitment. Computers in Human Behavior, v. 60, p. 86-96, 2016. http://doi.org/10.1016/j.chb.2016.02.006.

GUERRA, J. B. S. O. de A.; GARCI, J.; LIMA, M. de A.; BARBOSA, S. B.; HEERDT, M.

L.; BERCHIN, I. I. A proposal of a balanced scorecard for an environmental education program at universities. J. Clean. Prod., v. 172, p. 1674-1690, 2018.10.1016/j.jclepro.2016.11.179.

GUTIERRES, Henrique Elias Pessoa; CABRAL, Iran Araújo; SILVA, Rafaella Rodrigues da. A implementação de ações sustentáveis baseadas na Agenda Ambiental na Administração Pública (A3P): uma experiência extensionista no 
ambiente universitário. Revista Brasileira de Geografia Física, v. 12, n. 5, p. 19131933, 2019.

IARED, V. G.; OLIVEIRA, H. T. Concepções de Educação Ambiental e perspectivas pedagógicas de Professoras do Ensino Fundamental. Educação em Revista, v. 27, n. 2, p. 95- 122, 2011. Disponível em: http://dx.doi.org/10.1590/s010246982011000200006. Acesso em: 16 dez. 2019.

IBGE divulga as estimativas da população dos municípios para 2019. Agência IBGE Notícias, 28 ago. 2019. https://agenciadenoticias.ibge.gov.br/agencia-sala-deimprensa/2013agencia-denoticias/relea-ses/25278-ibge-divulga-as-estimativas-dapopulacao- dos-municipios-para-2019. Acesso em: 08 mar. 2020.

IBOPE. Desinformação é maior dificuldade para reciclagem no Brasil. 2018. Disponível em: http://www.ibopeinteligencia.com/noticias-epesquisas/desinformacao-emaiordificulda- depara-a-reciclagem-no-brasil/. Acesso em: 21 maio 2020.

JEPSON, P., Ladle, R.J. Nature apps: Waiting for the revolution. Ambio, v. 44, p. 827832, 2015. https://doi.org.ez24.periodicos.capes.gov.br/10.1007/s13280-015-0712-2.

KALOGIANNAKIS, Michail; PAPADAKIS, Stamatios. Combining mobile technologies in environmental education: a Greek case study. International Journal of Mobile Learning and Organisation, v. 11, n. 2, p. 108-130, 2017.

KAZA, Silpa; YAO, Lisa C .; BHADA-TATA, Perinaz; VAN WOERDEN, Frank. 2018.

What a Waste 2.0: a Global Snapshot of Solid Waste Management to 2050. Urban Development; Washington, DC: World Bank, 2018.

KLEIN, Flávio Bordino; GONCALVES-DIAS, Sylmara Lopes Francelino; JAYO, Martin. Gestão de resíduos sólidos urbanos nos municípios da Bacia Hidrográfica do Alto

RC: 89489

Disponível em: https://www.nucleodoconhecimento.com.br/engenharia-deproducao/tecnologias-da-informacao 
Tietê: uma análise sobre o uso de TIC no acesso à informação governamental. Urbe. Rev. Bras. Gest.

Urbana Curitiba, v. 10, n. 1, p. 140-153, Apr. 2018. https://doi.org/10.1590/21753369.010.001.ao10.

LAKATOS, Eva Maria; MARCONI, Marina de Andrade. Fundamentos de Metodologia científica. 5. ed. São Paulo: Atlas, 2010.

LEMOS, A. Cidade e Mobilidade. Telefones Celulares, funções pós-massivas e territórios informacionais. Matrizes, Revista do Programa de Pós-Graduação em Ciências da Comunicação, São Paulo, USP, ano 1, n. 1, p. 121-137, 2007.

LIAO, C.; LI, H. Environmental Education, Knowledge, and High School Students' Intention toward Separation of Solid Waste on Campus. Int. J. Environ. Res. Public Health, v. 16, n.9, 1659, May 2019.

MAQUILÓN, J.J.; MIRETE, A.; AVILÉS, M. La Realidad Aumentada (RA). Recursos e propostas para a inovação educacional. Rev. Interuniv. Formato. Profr., v. 20 , p. 183-203, 2017.

MARCHIORATO, Henderson Bueno. Educação Ambiental: a tecnologia a favor da natureza. Kínesis, v. 10, n. 23, p. 85-99, Jul. 2018.

MAROULI, C.; Duroy, Q. Reflections on the Transformative Power of Environmental Education in Contemporary Societies: Experience from Two College Courses in Greece and the USA. Sustainability 2019, 11, 6465.

MATTAR, F. Pesquisa de marketing. São Paulo: Atlas, 1996.

MOMBRINI, Magda Pires. A conscientização para reciclagem de resíduos sólidos domésticos como contribuição ambiental e forma de geração de trabalho digno: diagnóstico e contribuições para a implantação da coleta seletiva em Vila Velha-ES. RC: 89489

Disponível em: https://www.nucleodoconhecimento.com.br/engenharia-deproducao/tecnologias-da-informacao 
2005.159 f. Dissertação (Mestrado em Engenharia de Produção) - Universidade Metodista de Piracicaba, Santa BÁrbara D'oeste, 2005.

MORAN, José Manuel. A Educação Ambiental na Internet. Avaliando a EA no Brasil. Peirópolis: ECOAR, 2001.

NOBRE, Ivone. Plano de Gestão Ambiental 2011. Lisboa: Instituto da construção e do imobiliário, 2010.

NWAFOR, Michael Chigozie; IGBOKWE, Josephine C.; ALI, Adizetu A.; ONOH, ChiomaLevel of Awareness and Information Needs on Indiscriminate Dumping of Solid Waste Among Staff and Students of Nigerian Universities. Library Philosophy and Practice (e- journal), 2248, 2019.

OLIVEIRA, Djalma de Pinho R. Administração Estratégica na Prática. São Paulo: Atlas, 2011.

OLIVEIRA, Maria Angélica Figueiredo. Estratégia híbrida para o processo ensino aprendizagem baseada na participação ativa e avaliações integradas. 2019. Tese (Doutorado em Informática na Educação) - UFRGS, Porto Alegre, 2019.

ÓRUS, C.; BARLÉS, M. J.; BELANCHE, D.; CASALÓ, L.; FRAJ, E.; GURREA, R. The effects of learner-generated videos for YouTube on learning outcomes and satisfaction. Computers \& Education, 95, p. 254-269, 2016. DOI: 10.1016/j.compedu.2016.01.007

PAREDES-LABRA, J.; SIRI, I.-M.; OLIVEIRA, A. Preparing Public Pedagogies with ICT: The Case of Pesticides and Popular Education in Brazil. Sustainability, v. 10, $3377,2018$.

PĂVĂLOAIA, Vasile-Daniel et al. ESD for Public Administration: An Essential challenge for inventing the future of our society. Sustainability, v. 11, n. 3, 880, 2019.

RC: 89489

Disponível em: https://www.nucleodoconhecimento.com.br/engenharia-deproducao/tecnologias-da-informacao 
PEARSON, E.; TINDLE, H.; FERGUSON, M.; RYAN, J.; LITCHFIELD, C. Can we tweet, post, and share our way to a more sustainable society? A review of the current contributions and future potential of \#Socialmediaforsustainability. Annu. Rev. Environ. Resour., v 41, p. 363-397, 2016.

PEREIRA, Viviane Santos; ANTONIALLI, Luiz Marcelo. Ensino a distância: estratégias de uma universidade federal. Contextus, Revista Contemporânea de Economia e Gestão, v. 9, n. 1, p. 33-48, jan./jun. 2011.

PESSINI, Sandra. Global Advisor - Um mundo descartável. Comnunicação IPSOS, Brasil, 28 nov. 2019. Disponível em: https://www.ipsos.com/pt-br/global-advisor-ummundo- descartavel. Acesso em: 20 ago. 2020.

REBEHY, P. C. P. W.; COSTA, A. L.; CAMPELLO, C. A. G. B.; ESPINOZA, D. F.:

NETO, M. J. Innovative social business of selective waste collection in Brazil: cleaner production and poverty reduction. J. Clean. Prod., v. 154, n. 15, p. 462-473, June 2017.

RABU, Siti Nazleen Abdul; HUSSIN, Haniza; BERVELL, Brandford. QR code utilization in a large classroom: Higher education students' initial perceptions. Education and Information Technologies, v. 24, n. 1, p. 359-384, 2019.

RIBEIRO, Milena Missiano Comeron et al. Práticas de Divulgação, Conscientização e Capacitação para a Sustentabilidade uma Proposta para as Universidades Federais Brasileiras. Revista de Administração IMED, Passo Fundo, v. 8, n. 1, p. 146-168, ago. 2018. doi:https://doi.org/10.18256/2237-7956.2018.v8i1.2138.

RIGA, M.; STOCKER, M.; RÖNKKÖ, M.; KARATZAS, K.; KOLEHMAINEN, M.

RC: 89489

Disponível em: https://www.nucleodoconhecimento.com.br/engenharia-deproducao/tecnologias-da-informacao 
Extração de informações sobre ambiente atmosférico e qualidade de vida do twitter com O Uso de Mapas auto-Organizados. Revista de Informática Ambiental, v. 26, n. 1, p. 27-40, 2016.

RIEGER, O. Y. Opening up institutional repositories: social construction of innovation in scholarly communication. Journal of Electronic Publishing, v. 11, n. 3, Fall 2008. http://dx.doi. org/10.3998/3336451.0011.301

ROCHA, Paula Melani. A importância da educomunicação na formação de profissionais comunicação social na contemporaneidade, Communicatio, v. 41, n. 2, p. 192-205, 2015.doi: 10.1080 / 02500167.2015.1070186

RODRIGUES, B. Webwriting: redação \& informação para a Web. Rio de Janeiro: Brasport, 2006.

RODRIGUES, Gelze Serrat de Souza Campos; COLESANTI, Marlene T. de Muno. Educação ambiental e as novas tecnologias de informação e comunicação. Soc. nat., Uberlândia, v. 20, n. 1, p. 51-66, June 2008. http://dx.doi.org/10.1590/S198245132008000100003.

ROHRICH, Sandra Simm; TAKAHASHI, Adriana Roseli Wünsch. Sustentabilidade ambiental nas Instituições de Ensino Superior, um estudo bibliométrico sobre as publicações nacionais. Gest. Prod., São Carlos, v. 26, n. 2, e2861, 2019. https://doi.org/10.1590/0104- 530x2861-19

SHANA, Zuhrieh A; ABULIBDEH, Enas S. Engaging Students through Blogs: Using Blogs to Boost a Course Experience. International Journal of Emerging Technologies in Learning (iJET), v. 10, n. 1, p. 30-38, Feb. 2015. doi:http://dx.doi.org/10.3991/ijet.v10i1.4240.

SILVA, Pollyana Ferreira da. Limites e potencialidades da coleta seletiva de resíduos sólidos em municípios de médio porte: o caso de Barreiras-BA. 
Dissertação (Mestrado em Engenharia Urbana) - Universidade Federal de São Carlos, 2018.

SISTEMA NACIONAL DE INFORMAÇÕES EM SANEAMENTO BÁSICO (SNIS).

Diagnostico do Manejo de Resíduos Sólidos, 2019. Brasília, DF, 2020. Disponível em: http://www.snis.gov.br/downloads/diagnosticos/rs/2019/Diagnostico_RS2019.pdf. Acesso em: 16 dez. 2019.

SODRÉ, M. G. Consumidor e a Rotulagem Ambiental. 1997. Disponível em: http://ttp.unb.br/pub/UNB/admin/reciclagem/Cempre\%20-\%20n\%BA\%2034\%20 \%20junho- 1997.doc. Acesso em: 05 abr. 2020.

SOUTO-MAIOR, Joel. Manual de Planeação. Estratégica e Comunicativa. Ebook Kindle, 2013.

StefANI, G.; BeRnARDES, J. C.; BERNARDO, C. H. C. Comunicação e rede ambiental: análise das tics utilizadas pelo grupo de pesquisa em gestão e educação ambiental. Revista Científica ANAP Brasil, v. 9, n. 14, p. 88-96, 2016.

TAN, Elaine. Informal Learning on YouTube : Exploring Digital Literacy in Independent Online Learning. Aprendizagem, Mídia e Tecnologia, v. 38, n. 4, p. 463 - 477, 2013. doi:10.1080 / 17439884.2013 .783594$.

TARDIF, M.; LESSARD, Claude. 0 trabalho docente: elementos para uma teoria da docência como profissão de interações humanas. 2. ed. Petrópolis: Vozes, RJ, 2005.

TAUCHEN, J.; BRANDLI, L. A Gestão ambiental em instituições de ensino superior: modelo para implantação em campus universitário. Gestão \& Produção, v. 13, n. 3 , p. 503- 515, 2006. 
TURAN ÇIMCIR, B.; UZUNBOYLU, H. Awareness Training for Sustainable Development: Development, Implementation and Evaluation of a Mobile Application. Sustainability, v. 11, n. 3, 611, 2019. https://doi.org/10.3390/su11030611

WIRTZ, Bernd W.; BIRKMEYER, Steven. Mobile government services: An empirical analysis of mobile government attractiveness. International Journal of Public Administration, v. 41, n. 16, p. 1385-1395, 2018.

WU, J.; GUO, S.; HUANG, H.; LIU, W.; XIANG, Y. Information and communications technologies for sustainable development goals: state-of-the-art, needs and perspectives. IEEE Communications Surveys \& Tutorials, v. 20, n. 3, p. 2389-2406, 2018.

ZAGO, Valéria Cristina Palmeira; BARROS, Raphael Tobias de Vasconcelos. Gerenciamento de resíduos orgânicos no Brasil: ordenamento jurídico à realidade. Eng. Sanit. Ambiente. Rio de Janeiro, v. 24, n. 2, p. 219-228, abril de 2019. https://doi.org/10.1590/s1413-41522019181376 .

ZANELA, Mariluci. O professor e o "laboratório" de informática: navegando nas suas percepções. 2007. 86 f. Dissertação (Mestrado em Educação) - Universidade Federal do Paraná, Curitiba, 2007.

ZHANG, A.; VENKATESH, V. G.; LIU, Y.; WAN, M.; QU, T.; HUISINGH, D. Barriers to smart waste management for a circular economy in China. Journal of Cleaner Production, v. 240, 118198, 2019.

ZHANG, H.; LIU, J.; WEN, Z.-G.; CHEN, Y.-X. College students' municipal solid waste source separation behavior and its influential factors: A case study in Beijing, China. J. Clean. Prod., v. 164, p. 444-454, 2017.

ZSÓKA, Á.; SZERÉNYI, Z.M.; SZÉCHY, A.; KOCSIS, T. Greening due to environmental education? Environmental knowledge, attitudes, consumer behavior

RC: 89489

Disponível em: https://www.nucleodoconhecimento.com.br/engenharia-deproducao/tecnologias-da-informacao 
and everyday pro- environmental activities of Hungarian high school and university students. J. Clean. Prod., v. 48, p. 126-138, 2013.

Enviado: Junho, 2021.

Aprovado: Junho, 2021. 